\title{
Logistics performance measurement system for the automotive industry
}

\author{
Martin Dörnhöfer $^{1} \cdot$ Falk Schröder $^{2} \cdot$ Willibald A. Günthner ${ }^{1}$
}

Received: 7 March 2016/ Accepted: 17 June 2016/Published online: 29 June 2016

(C) The Author(s) 2016. This article is published with open access at Springerlink.com

\begin{abstract}
Logistics can be seen as a key competitive factor in the automotive industry due to the rising number of model variants and options. With the increasing importance of logistics (Gunasekaran et al. in Int $\mathbf{J}$ Prod Econ 87(3):333-347, 2004), the evaluation of logistics effectiveness and efficiency is gaining increased attention. Logistics performance management (PM) is the key to quantifying the current state and improvement potentials within logistics. To account for the increasing importance of a supply chain, logistics PM needs to start at the supplier and reach at least until the original equipment manufacturer's (OEM) assembly line. Furthermore, logistics PM needs to be in line with the latest logistics concepts, mainly based on lean logistics. In contrast to the great importance of logistics PM, the literature analysis shows a limited availability of logistics performance measurement systems (PMS), which are actually applicable to industry within a lean logistics context. The systems in the literature are either too high level to be useful to practitioners (e.g. supply chain-orientated systems) or too narrow in focus, and therefore do not cover the supply chain and lean perspectives. In the following paper, a logistics PMS is developed which allows for assessing the effectiveness and efficiency of current logistics processes. The developed
\end{abstract}

Martin Dörnhöfer

doernhoefer@fml.mw.tum.de

Falk Schröder

falk.schroeder@volkswagen.de

Willibald A. Günthner

guenthner@fml.mw.tum.de

1 Lehrstuhl für Fördertechnik Materialfluss Logistik, Technische Universität München, Garching, Germany

2 Volkswagen AG, Konzernlogistik, Wolfsburg, Germany approach incorporates the latest logistics concepts in the automotive industry, integrates a process orientation with a supply chain perspective, and is defined with the specificity required to enable the implementation within a specific industry context and triggers continuous improvement. The suggested framework is evaluated in an automotive context, presenting a short case study on the implementation of the proposed framework at two sites of a German automotive OEM. Furthermore, future application potentials and development needs are summarised. The paper's contribution to the literature is in the field of logistics PM, specifically in the automotive industry. It offers a new approach, applicable to automotive logistics, which follows lean principles. For industry, this paper provides specific suggestions for a PMS, as well as performance indicators to holistically monitor the logistics chain. While being generic in terms of its definition, it can be seen as specific enough to be applicable in industry with limited adjustments. It provides practitioners with answers to the question of which performance indicators to use in today's automotive logistics chain and which indicators serve as a base for continuous improvement.

Keywords Performance - Management - System · Automotive $\cdot$ Logistics $\cdot$ Supply chain

\section{Introduction}

Businesses nowadays function in an increasingly challenging environment [2] which is reflected in increasing product complexity in manufacturing industries, driven by customer demand for individualisation. In addition, cost pressures remain high. The automotive industry has already been facing this challenge for several years. It can therefore 
be seen as a good research base in the supply chain, as well as in logistics contexts. Efficient manufacturing and logistics processes are a key competitive advantage, next to the capability of supplying the right product to the customer with an optimum lead time.

Responding to these challenges extends logistics processes' scope beyond the formerly known tasks [1]. Space limitations at the assembly line lead to the picking and sequencing of parts, a core logistics activity nowadays. With an increased focus on the trade-off between stock reduction and higher delivery frequencies, the number of parts delivered by just-in-sequence processes is also rising. At all times, on-time parts availability at the assembly line is essential to ensure high manufacturing capacity utilisation.

Further improving logistics efficiency and effectiveness requires transparency of the current processes. A proper PMS is seen as a key for creating transparency and a trigger for improvement ideas as you cannot improve that which does not get measured [3]. In addition, ensuring the PMS is in line with the company's strategy will enhance strategy fulfilment by lower level management and therefore additionally lead to increased strategy achievement [2]. As competition is shifting from single companies towards supply chains, the scope of PMS needs to be extended to incorporate a supply chain perspective. Supply chain PMS, if implemented correctly, has already proved its potential $[4,5]$. In the automotive logistics context, a research gap in respect of the logistics PMS which integrates the supply chain perspective, while being specific enough for practitioners to be useful, can be identified $[6,7]$.

The latest trends in automotive logistics further emphasise the requirement to rethink logistics PMS [8]. The trend of outsourcing will, for example, also require a holistic measurement of performance [9] and provide a rationale for focusing on logistics performance measurement [10], too, due to the increasing relevance of logistics. Latest changes on a process level are adding to this as production concepts are transformed from mass production to lean production. In the transition to a lean environment, based on continuous improvement and standardisation of the improved concepts, a PMS allowing the comparison of different concepts becomes even more important [11]. The need to adapt PMS in this context is highlighted in the literature, but not yet thoroughly researched [12]. To support continuous improvement of the newly implemented lean production and logistics processes, PM needs to be aligned with those concepts [13] and needs to support the identification of improvement potentials [11].

Considering both, the mentioned research gap in PMS for the supply chain and the latest changes in the process landscape in automotive logistics, the research question arises: How should a suitable PMS for automotive logistics be designed? Addressing this question needs to consider the requirements for PMS resulting from latest literature, from the processes and logistics concepts as well as user requirements towards PMS.

We focus our research on automotive logistics, as the automotive industry is advanced in terms of supply chain management and lean logistics and therefore offers a good research base [7]. Our suggested methodology is a multimethod approach. Firstly, a structured literature review on the current state of PMS in (automotive) logistics context is provided. As we were not able to identify an approach which satisfies today's industrial needs and challenges, we propose a PMS in the context of lean logistics. The development follows a typical development approach in PMS research which is modified to account for the identified research gaps. Our development process includes the latest developments in industry regarding logistics processes and the supply chain perspective-from the supplier to the final assembly line. For evaluation purposes, a short case study on the application of the proposed PMS within the automotive industry at two sites of a German OEM is provided, applying the case-study methodology. We describe the methodologies for PMS development and evaluation in detail in Sect. 3 of this paper, after the presentation of our findings from the literature review. Figure 1 highlights the methodologies applied throughout the paper and their contribution to the research question.

\section{Literature review}

The following part summarises our findings from a structured literature review on PMS in an automotive logistics context. We focus on the design of PMS and specific PMS frameworks proposed in a logistics context. As lean production systems have dominated in the automotive industry since the introduction of the Toyota Production System [14], we have also included lean manufacturing and lean logistics-related PMS.

Firstly, we summarise our literature review on the design criteria for PMS and specify the results for an automotive logistics context. Secondly, we discuss a selection of identified PMSs and their evaluation in respect of the aforementioned criteria.

\subsection{Design criteria for PMS}

Conducting a paper search in scholarly databases regarding research on the design criteria for PMS, especially in a logistics or supply chain context, highlights that the literature published over the last few years is vast. Reviewing the papers leads us to conclude that the design criteria mentioned in the literature mainly differ by their names, or 
Fig. 1 Overview on methodologies applied throughout the paper
Methodology

A Structured literature review

B Generic PMS development

C Case-study based evaluation
Questions answered

Central research question

- How applicable are current PMS in literature considering the design criteria and requirements from current automotive logistics environment?

- What are design criteria for PMS in academic literature?

- Which current PMS are proposed in literature?

- How should a suitable PMS for today's automotive logistics environment be designed?

- Is the PMS developed in (B) suitable in an industry context and which changes are required for its implementation in that environment? due to a specific research focus, e.g. an industry or a local area, but are similar in their core intent. We therefore only present a short summary of the main findings we deem relevant in an automotive logistics context.

As mentioned before, a supply chain or inter-organisational perspective, needs to be included in PMS today $[1,15,16]$, especially for the area of logistics whose function is the provision of the physical link between companies within the supply chain. As the automotive industry is said to be advanced in supply chain topics, and is faced with increasing levels of outsourcing, this aspect further increases in importance. This is also emphasised by the lean logistics context, which requires a focus on the value chain instead of ending with company borders-with a lean supply chain being the ultimate goal [11].

In addition, process orientation is a key $[10,17]$ to identifying optimisation potentials along the processes, with the customer's requirements [18] being the trigger for every improvement. Furthermore, by applying process orientation, an optimisation within functional silos is avoided, a potential risk of PMS designed without a process perspective.

The inclusion of a balanced set of non-financial and financial metrics $[19,20,21]$, leads to a holistic assessment, directed towards long-term improvements instead of, for example, short-term financial ones. The PMS should be orientated towards increasing the efficiency and effectiveness of actions [12, 22] alike.

Moreover, the PMS's design should always consider the benefit created by the PMS. Defining a value-adding PMS is essential. This also involves designing a PMS which supports continuous improvement initiatives [23]. This is in line with the principles of lean management, which demand ongoing improvement initiatives (jap. kaizen) $[14,24]$. A properly designed PMS is required to highlight improvement potentials. Process orientation needs to be further detailed by a focus on actionable KPIs, and designed based on cause-and-effect relationships [12, 25]. The right trade-off between detailed KPIs for single process steps and more high level KPIs covering the whole process is important. In addition to monitoring the material flow, especially in lean logistics environments, a monitoring of information process KPIs is perceived as significant [11], as the importance of information processes is rising, e.g. with decreasing stock levels.

For a continuously applied PMS, its efficiency for constantly managing the KPIs is also an important criterion [26] which may be difficult to evaluate upfront, but which should be accounted for, e.g. by a focused selection of required metrics, and a focus on metrics that can be updated automatically using data in the IT systems.

While evaluating the PMS in the literature, one needs to remember that designing a PMS which fulfils all the design criteria remains a vision [15] — the criteria therefore have to be prioritised considering the application context, as indicated before.

\subsection{Evaluation of performance measurement systems from the literature}

In the following, we summarise our literature review on logistics PMS, with special attention on lean logistics. The approaches are evaluated using the design criteria mentioned before.

We applied a structured paper search to identify relevant PMS approaches. Keywords for our search included lean, logistics, performance and measurement according to our research objective [27]. Using scholarly databases, we identified a limited number of papers which complied with our search criteria, the majority of them having been published since 2010, indicating a recent resurgence of research interest in the field. 
A majority of the identified papers relate to lean manufacturing which highlights the lack of lean logistics PMS research. Considering this, we extended our search to logistics performance measurement literature published before the introduction of lean logistics, to account for the main developments in logistics performance measurement over the last decades.

As representative PMS approaches published before the introduction of lean, we selected those by Bentz [28] and Syska [29]. The approach proposed by Bentz [28] can be characterised as a framework for manufacturing enterprises with a focus on material flow, mainly evaluating the financial perspective. The definition of performance indicators is based on selected cost drivers within the material flow (e.g. available logistics space as a driver for warehousing costs). While mainly cost-focused, the resulting indicators are partially linked to provide a perspective on the logistics' overall efficiency. Nevertheless, the proposed system is solely internally focused and only applicable for one company or manufacturing site.

The PMS of Syska [29] is based on a system of systematically linked logistics targets, focusing only on internal logistics processes. In addition, the approach considers the material flow, but, does not provide a perspective on the information flow. The objective of reduced logistics costs and increased parts availability are set as dominant targets for the proposed PMS. Increasing parts availability focuses on lead-time reduction and other, mainly manufacturing-related, measures. The author also highlights the need for a reduction in the handling time between manufacturing steps, but does not include this aspect in the PMS. Therefore, logistics aspects are not covered holistically. This is due to the aspect of the handling time being linked to planning and information flow in Syska's argument which is outside the scope of the approach. Lead times within logistics are only included when it comes to distribution processes. The aspect of cost monitoring includes all costs occurring within logistics and manufacturing, from personnel costs to machine set-up costs. Summarising the discussion, the proposed approach includes a detailed set of metrics along the logistics and manufacturing processes, but is internally focused, thus missing some important logistics process metrics; it therefore does not provide a holistic perspective.

In contrast to those two approaches, latest research includes a lean manufacturing and logistics perspective considering the currently dominant production concept [30].

Based on the main research question, clustering the remaining search results in respect of PMS leads us to define three clusters of work. The first group focuses on an assessment of the implementation of lean principles. The second assesses the performance of a production system which applies lean manufacturing principles. A third cluster consists of papers evaluating the extent to which a different degree of lean implementation leads to various efficiency levels in the manufacturing process. We provide a short evaluation of the proposed PMS within each cluster with regards to our research objective in the following:

The first cluster of research is mainly based on qualitative, questionnaire-based assessment. The authors derive questionnaires from lean principles and the assessment focuses on the extent of the lean-compliance of the applied manufacturing system. Soriano-Meier and Forester [31] offer an approach to also compare the degree of lean implementation among companies as they calculate an overall score. In contrast, Karlsson and Ahlström [30] assess lean implementation by analysing the determinants of lean production, e.g. reduction in waste by decreasing lot sizes. They apply metrics to reflect the implementation and point out an overall direction for each metric (increase and decrease).

Those approaches show a high level of operational applicability and are highly process-focused. Furthermore, they point out improvement directions, thus enabling continuous improvement. This leads to added value for the user, insofar as there is agreement that a higher degree of lean implementation is beneficial to business. In contrast, these approaches lack integration or linkage into an overarching PMS and can be seen as stand-alone tools (e.g. no transparency on the implication of improved "leanness" for overall profitability is provided). Furthermore, a frequent evaluation is time consuming due to the qualitative nature of the assessment. In addition, the evaluations only show a subjective character as, to some extent, they reflect the opinion of the evaluator. A supply chain perspective is missing with the systems being designed only for a single company, not for a supply chain.

The second cluster is specifically designed to evaluate performance. Based on the SCOR (supply chain operations reference) model, Arif-Uz-Zaman and Nazmul Ahsan [32] propose a lean performance evaluation model. Standard performance metrics suggested within the SCOR approach are combined with lean performance metrics. The PMS design follows a fuzzy-approach to align the methodology with the company's strategy. Behrouzi et al. [13] propose a limited set of performance indicators for the lean supply chain environment based on expert opinions and a principal component analysis. Moreover, they apply the clustering of metrics towards shared objectives (e.g. quality improvement). While offering a selection of possible metrics, the authors do not elaborate on the selection of critical metrics in terms of lean assessment.

A second stream of research is based on value stream mapping (VSM) to assess the performance of lean management systems, e.g. the approach of Wee and $\mathrm{Wu}$ [33], 
an approach designed originally to identify waste and redesign processes, rather than measuring overall performance. Wan et al. [34] propose to combine data envelopment analysis (DEA) and VSM to calculate an aggregated leanness score based on the target fulfilment of the dimensions of cost, time and added value. The quality dimension is seen to be reflected in those dimensions. Generally, the approaches based on VSM lack a holistic view as they only focus on one single value stream and can thus be considered as a standalone tool, rather than a continuous monitoring tool. Wan et al. [34] address this aspect by providing an outlook for a continuous application, but also highlight the remaining challenges for an evaluation of multiple value stream environments, as well as difficulties for users in the identification of improvement ideas. In addition, an integration into a companywide PMS remains unanswered.

Today, research on the correlation of the degree of lean implementation and actual performance improvements focuses on selected lean principles and their realisation. Agus and Hajinoor [24] assess the link between lean principles and financial performance. They focus on the link between lean manufacturing and business performance, also accounting for quality performance. Based on an empirical survey, selected aspects are presented to be monitored within a lean supply chain PMS. The work confirms that several lean principles, e.g. the reduction in set-up times, continuous improvement programmes, realisation of the pull principle, the shortening of lead times, as well as smaller lot sizes, show a positive influence on product quality performance [24]. Fullerton and Wempe [35] indicate the need for non-financial metrics and the involvement of shop-floor employees in the overall lean implementation process, with the link between non-financial metrics, the overall management accounting system and continuous improvement processes indicating the need for further research.

Other researchers propose a selection of metrics for lean performance evaluation along the implementation journey and bear in mind the criticism that current PMS, in the context of lean introduction, is too static. They mainly focus on the added value time, defects and productivity. An application, in the context of a continuous improvement cycle, is suggested [36]. Whilst these approaches show strengths regarding applicability during implementation, they are not designed for continuous monitoring and integration into companywide monitoring systems.

Figure 2 summarises the discussion using selected design criteria (see Sect. 2.1).

\subsection{Identification of research needs}

Our literature review identified initial approaches to evaluate performance within a lean context. However, within these approaches, we could not identify an approach that fits the stated requirements of quantifying the performance

\section{Evaluation of literature streams in a lean logistics context}

\begin{tabular}{|c|c|c|c|c|}
\hline \multirow[b]{2}{*}{ Selected design criteria for PMS } & \\
\hline & $\begin{array}{l}\text { Traditional } \\
\text { logistics } \\
\text { PMS literature }\end{array}$ & $\begin{array}{l}\text { Lean implemen- } \\
\text { tation assessment } \\
\text { oriented literature } \\
\end{array}$ & $\begin{array}{l}\text { Lean performance } \\
\text { assessment } \\
\text { literature }\end{array}$ & $\begin{array}{l}\text { Value stream } \\
\text { mapping } \\
\text { based literature }\end{array}$ \\
\hline - Supply chain orientation & & & & \\
\hline $\begin{array}{l}\text { - Incorporating multi-dimensional } \\
\text { objectives }\end{array}$ & & & & \\
\hline $\begin{array}{l}\text { - Holistic assessment of logistics processes } \\
\text { including material and information flow }\end{array}$ & & & & \\
\hline - Integrating the lean principles & & & & \\
\hline $\begin{array}{r}\text { - Continuous improvement support, by } \\
\text { - systematically linking KPIs } \\
\text { - logistics process orientation }\end{array}$ & & & & \\
\hline - Data availability oriented KPI selection & & & & \\
\hline $\begin{array}{l}\text { not fulfilled } \\
\text { partially fulfilled } \\
\text { fulfilled }\end{array}$ & & \multicolumn{3}{|c|}{$\begin{array}{l}\text { Todays literature often manufacturing driven or } \\
\text { focussed leading to lack in lean logistics } \\
\text { oriented PMS today }\end{array}$} \\
\hline
\end{tabular}

Fig. 2 Evaluation of the literature 
Fig. 3 Summary of requirements for an automotive logistics PMS in the context of lean logistics

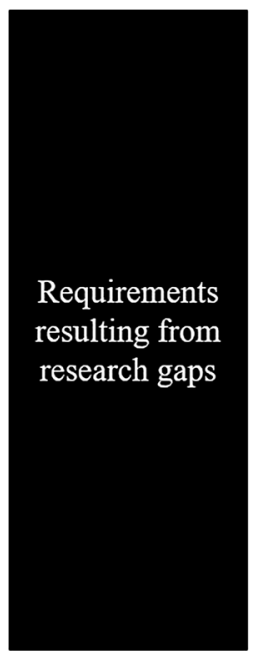

- Integration of lean logistics objectives and principles into PMS to support an ongoing implementation process

- Holistic, company-overarching assessment of the logistics processes, taking material- and information-flow into account

- Considering the multi-dimensional objectives of todays businesses

- Support of the continuous improvement process using process oriented, specific KPIs which are aligned within the PMS horizontally and vertically

- Enable a standardized rollout of the PMS internally, as well as externally

- Consider data availability for automized KPI reporting in industry to support current and available KPIs of the automotive supply chain including the elements of lean logistics. Most approaches are lean manufacturingrelated and do not consider logistics. In the context that current research emphasises the importance of performance evaluation during lean implementation [36], and considering the fact that automotive logistics currently is in the transition phase to lean logistics, this becomes even more important. A lack of understanding of lean performance due to the unavailability of adequate PMS support is found to be a driver for a failing lean implementation [13] and the non-acceptance of those concepts in industry.

As lean implementation is seen as an ongoing, continuous process; a proper PMS does not only need to account for the start of implementation, but also needs to be aligned with a company or manufacturing PMS and support the transition journey to lean. This has not yet been considered broadly in the literature, nor has it been rolled-out to logistics PMS.

Being aligned with the overarching company's PMS and objectives is important, as lean implementation is not the only objective [37]. A first notion is provided by Monden [38], who links lean assessments and strategic objectives, but remains unspecific on the required set of performance indicators for the different management levels. In our literature review, we were also not able to identify any approaches which provide this overall link.

In addition, regarding a holistic assessment, we were not able to identify any approaches which systematically consider the importance of information processes within logistics and provide a tool for evaluating information quality. Current approaches are dominated by subjective questionnaire-based evaluations (e.g. [39]).

We conclude that PMS, in the context of lean, seem to be too operationally focused and only measure the lean implementation. The systems lack an integration of the company's objectives, as well as the supply chain perspective, due to a solely internal focus. This is in contrast to the general approaches in PMS research, which are considered as being too simplistic, too high level and not specific enough [2], as is the supply chain literature [40].

Figure 3 summarises the resulting requirements, taking the identified research gaps into account.

Based on the identified research gap, the remainder of the paper focuses on the development of a PMS to holistically evaluate logistics performance. In addition, the approach takes lean logistics principles and their current application in the automotive industry into account. As the proposed approach is not solely focused on lean, and integrates all the relevant objectives within automotive logistics, we aim to provide researchers and practitioners with a PMS which is applicable beyond the lean implementation. Furthermore, the proposed PMS includes a perspective on material and information flow processes to provide a holistic logistics assessment.

Our approach is designed to be applicable in a supply chain context and, at the same time, is developed specifically to be helpful for practitioners, including specific performance indicators (PI) across all levels of hierarchy within the companies. In addition, we aim to derive an enabling PMS which is focused on triggering improvements and is used by lower management levels and employees [41] to increase the application of continuous improvement processes.

\section{Methodology}

In the following, we describe the methodology used to develop and evaluate the PMS. We followed a systematic process described in Sect. 3.1 to develop a PMS applicable in automotive logistics in line with recommendations in the literature [12]. A case study was used to evaluate the 
framework (see methodology in Sect. 3.2). The case-study approach was selected for this paper as it is seen as one of the most suitable approaches to present research results in supply chain and logistics management [42], especially in applied research [43].

\subsection{Development approach and process}

The development of our proposed PMS started with a definition of the objectives for the PMS's application [3] in Sect. 4. For the development of the generic PMS framework, we followed a five-step process:

1. Analysis of objectives in automotive logistics.

2. Development of reference processes within automotive logistics.

3. Determination of the relevant performance dimensions and top-level key performance indicators (KPI).

4. Detailed breakdown of evaluation aspects along the logistics process.

5. Definition of performance indicators (PI) for selected evaluation aspects.

With this development process, we followed the approach proposed by Göpfert [44], in combination with the one of Syska [29]. Göpfert [44] provides an overall process for PMS development, while Syska [29] provides the idea of splitting the process into a generic PMS development and a customisation phase. In addition, our process reflected the recommendations of several researchers (e.g. [12, 23, 25, 45, 46]).

Starting with an analysis of the objectives within automotive logistics, we aimed to identify typical objectives in the current lean logistics environment and beyond. The analysis provided the base for identifying the relevant performance dimensions with step three of the proposed methodology, and provided the link to overall company and supply chain objectives.

A detailed process analysis in automotive logistics enabled us to propose a PMS which is based on the underlying processes. This aspect is also pursued at a supply chain level by the SCOR model [32, 47], and followed in our approach on a more detailed, specific process level. We judged a process orientation important for enabling continuous improvement. During this step, we aimed to develop a reference process of the industry as a base for our PMS definition.

Using the combination of process analysis and logistics objectives not only enabled us to break down the objectives into each process step, but also to identify the relevant performance dimensions to be included into the PMS. This served as a starting base for the identification of top-level KPIs, as well as for the breakdown to PIs along each process step later on to also ensure specificity [48].
When selecting relevant PIs, we focused on cause-andeffect relationships to ensure continuous improvement support on the lower level while, at the same time, ensuring benefits added to the increased achievement of the objectives on the higher level metrics.

To ensure practical relevance, all the steps were supported by a broad analysis of publically available company documents and standards within the automotive industry (e.g. from the German association of automotive industry), as well as several interviews with logistics experts and managers in the automotive industry. By doing so, we hoped to not only propose a new theoretical framework, but also to focus on its applicability and added value to the industry.

After the generic PMS development, one modification step was proposed as in Syska [29], i.e. step six in the overall development process.

6. Company-specific adjustment of the suggested PMS framework (e.g. weighting of objectives, adaption of PMS to processes, complement suggested KPIs).

The objective of the last development step of the PMS was its adjustment to company-specific objectives, their processes, required data sources and IT systems. For the specific company context, this was an opportunity to include experience and potentially additional important KPIs from expert discussions, and to fit the proposed approach into existing reporting systems.

Using this approach, we accounted for the finding that defining a PMS in industry is not only about a greenfield development of a "should-be" PMS, as is often suggested in the literature, but also about its integration and the coordination of existing metrics [49]. By applying quantitative and qualitative methods, e.g. interviews, observation and participation in meetings, action research, review of company documents and publications, an applicable and enabling PMS [50] for the specific company context was derived.

\subsection{Evaluation methodology}

The evaluation methodology was designed to allow an evaluation of the applicability of the proposed PMS framework in industry, the assumed objectives, as well as the processes. In this context, the selection of KPIs and PIs within our framework was tested applying qualitative and quantitative methods. Furthermore, applying the PMS within an automated KPI dashboard allowed the evaluation of the automatic data evaluation. In addition, we included an assessment of the usefulness of the system for identifying continuous improvement potentials-one of the main objectives during development. 
Our methodology used elements of an explanatory case study focusing on the applicability of the proposed PMS. In addition, it could also be called an exploratory case study [51] when it came to understanding the metrics used currently within the company, their alignment with the proposed PMS and the integration of the company-specific ones into our framework during the implementation step. We therefore evaluated the framework using a case study at two manufacturing sites of a German automotive OEM (for details, see Sect. 5.1).

For evaluation purposes, we used a combination of workshops across the logistics functions, i.e. interviews, documents and data analysis. The participants are distributed across all levels of hierarchy, from operative level up to logistics management of the different sites.

At the beginning, a first round of workshops was conducted with the aim of aligning the logistics objectives found in the literature with the ones used on-site. Based on that, we proposed an open workshop format to collect the required PIs from logistics experts within the focus company. The focus was on the transparency of the PIs collected at the time, their relevance according to the experts' judgements, as well as the additional PIs that were considered relevant for monitoring and improving logistics processes. In this context, we proposed an open workshop format, not presenting our framework in detail upfront, so as to ensure non-biased discussion with the experts.

Afterwards, the clustering and consolidation of all the PIs identified in the open workshop rounds was applied. We compared our proposed PIs with the ones identified in the experts' workshops. PIs which were not named by the experts, but proposed in our PMS, were highlighted and discussed in respect of their added value in a follow-up meeting. Additional PMs deemed relevant from an expert perspective were added to our proposed framework, as was the case also in step 6 of the development process in the case of a typical implementation journey of the PMS. The resulting PMS draft was aligned in another round of workshops and additional interviews.

After the modification of the detailed definition of the PMS and each metric (e.g. alignment with data sources, adding responsibilities), the system was implemented and data evaluation started, as well as a dashboard allowing PI evaluation launched. Based on that, a quantitative evaluation of each metric was started, which also highlighted initial improvement potentials.

\subsection{Scope of the PMS framework}

The scope of our logistics PMS framework covers the whole automotive supply chain, ranging from the suppliers to the point-of-use within the automotive OEM's manufacturing site (e.g. the final assembly or body-shop line).
For development purposes, we split the automotive supply chain into supplier-customer relationships at each stage, e.g. first-tier supplier-OEM, second-tier-first-tier supplier. For the remainder of the paper, we concentrate on the relationship first-tier supplier-OEM as, from a lineback perspective, this is the first relationship in the chain starting from the logistics' customer "manufacturing line". Furthermore, based on the literature and our experience, the highest process variety exists in this relationship, which allows a PMS framework derived based on this relationship to be transferred to other segments of the chain later on. Each segment showing the customer-supplier relationship is analogous to the primary scope of the developed PMS. By ensuring shared objectives across the supply chain, as well as aligned, standardised KPIs, we ensure a consistent PMS across the whole supply chain. This vision offers opportunities for all the partners to benefit from a shared PMS which is linked to the objectives of the whole chain, and suitable for application in a supply chain context [18].

When applying lean logistics principles, the focus is on the value stream - the process of value creation-instead of functional silos. The value stream in our context starts from the manufacturing line, which can be seen as an interface for translating the voice of the customer to logistics (e.g. the assembly takt time reflects the customer's takt, the material demand of the assembly line reflects actual customer orders). Nevertheless, besides a value stream-and therefore process perspective-our framework has to be designed in such a way that it considers typical organisational set-ups within the logistics function of companies within the automotive chain today. This allows e.g. for the assignment of managers along the process who are responsible for improvements. Resulting from the discussion that employees should be able to improve the PIs against which they are monitored, we judge this aspect important and as a trade-off between purely process oriented design and the traditional functional silos.

\section{Performance measurement system for the automotive logistics chain}

The following section summarises the main results of the PMS development process. While presenting the full scope for the first stages of the methodology, we focus on inbound logistics processes for the demonstration of specific KPIs from step 2 until the end of the case study ${ }^{1}$ due to the length limitations of this paper.

In terms of our focus, we assumed it valid to concentrate on the OEM and the link to the first-tier supplier. By doing

\footnotetext{
${ }^{1}$ Similar results are available upon request from the authors for the full scope of the developed PMS.
} 
so, we considered the OEM's leading and coordinating role within an automotive supply chain which is found in supply chain research [9]. Nevertheless, the roll-out to the whole chain needs to be kept in mind to create a valid and holistic PMS structure. This is in line with our objective of a linked PMS and its stepwise roll-out to the partners within one supply chain, e.g. to Tier 1 suppliers and logistics service providers.

\subsection{Analysis of logistics objectives}

Several authors report on logistics objectives, but only a limited number on specifics within the automotive industry can be found in publicly available sources. It is mainly world-class operations which can be found as an overarching target for manufacturing and logistics, including high-quality processes throughout the company [10].

Broken down to logistics, typical objectives are the achievement of cost advantages and the realisation of service leadership to realise price premiums. For logistics, this is reflected in the dimensions of increased productivity, quality and customer satisfaction [18]. Productivity includes capital investment optimisation (e.g. for logistics equipment and buildings) and the reduction in operational expenses (e.g. personnel costs in warehousing, transportation costs) - both measured against the throughput of the system. In addition, especially in logistics, optimised inventory levels are key [10] not only within a company, but also across the supply chain [52].

Customer satisfaction (in terms of our definition, the logistics' customer manufacturing line) includes the improvement of customer service, e.g. in terms of lead time [10] to the level demanded by the customer, and on-time delivery.

In areas where logistics is closely interlinked to operations, the dimension of flexibility towards changes within the operations environment also needs to be supported $[17,53]$, reflecting an additional objective in logistics.

Our analysis of company documents and interviews highlights how the trade-off between different objectives is handled with varying priorities in different companies. There are cultural differences, e.g. Japanese manufacturers focus more on quality and customer satisfaction, whereas Western companies tend to emphasise the productivity dimension first. In addition, improvements are orientated more towards the short term in Europe, in contrast to Japan [17].

Over the last few years, the prioritisation of objectives has also shifted. The efficiency of logistics has become more important than a cost-only perspective. In addition, with the introduction of lean logistics, the focus on the quality of logistics and logistics processes has increased. This also includes an emphasis on information quality, as a consequence of further reduced inventories, and its necessity for a stable process.

A typical trade-off that can be found in automotive logistics is the prioritisation of cost reduction or increased productivity, as long as on-time delivery and the demanded logistics quality is maintained [54]. A perspective is followed in the remainder of the paper.

Furthermore, we used the term effectiveness to summarise logistics effort and quality dimension, as effort can only be measured in context with quality (logistics efforts not showing the provided quality can be seen as waste in lean thinking). Effectiveness therefore reflects what can be seen from the customer's point of view [18]. In addition, efficiency reflects the productivity dimension.

Flexibility in automotive logistics in the remainder of the paper is the capability of maintaining or further improving the current level of efficiency and effectiveness in the future, also in case of changing influencing factors on logistics (e.g. decreasing production volumes).

In addition, our analysis showed the need for flexibility to add company-specific objectives, such as green logistics being derived from the strategy objective of "green-manufacturing" in some companies. As not all companyspecific objectives can be covered in the generic PMS, the framework needs to provide flexibility for their integration.

\subsection{Process analysis}

The following process analysis aims at identifying the main processes in automotive logistics which need to be reflected within our PMS framework. In general, while detailed processes vary even within companies, the overall structure and process steps applied are found to be quite similar. This has also been found in recent works by other researchers [3], justifying our approach to developing a generic PMS based on our process analysis - the derived process shall be named "reference processes in automotive logistics".

Figure 4 presents an overview of the results of our analysis with a focus on the inbound logistics processes. To account for the increasing importance of the information flow, in addition to the material flow shown in the figure, demand forecasting and material call-off processes have been considered for the following PMS development.

With the introduction of lean production and logistics throughout recent years, we found that the number of logistics process variants has increased significantly from the previously dominating concepts of full truck load (FTL) and area forwarding (AF). For example, crossdocking processes have been introduced, as the inbound logistics' reaction to decreased lot sizes and increasing delivery frequencies, to enable efficient transportation 


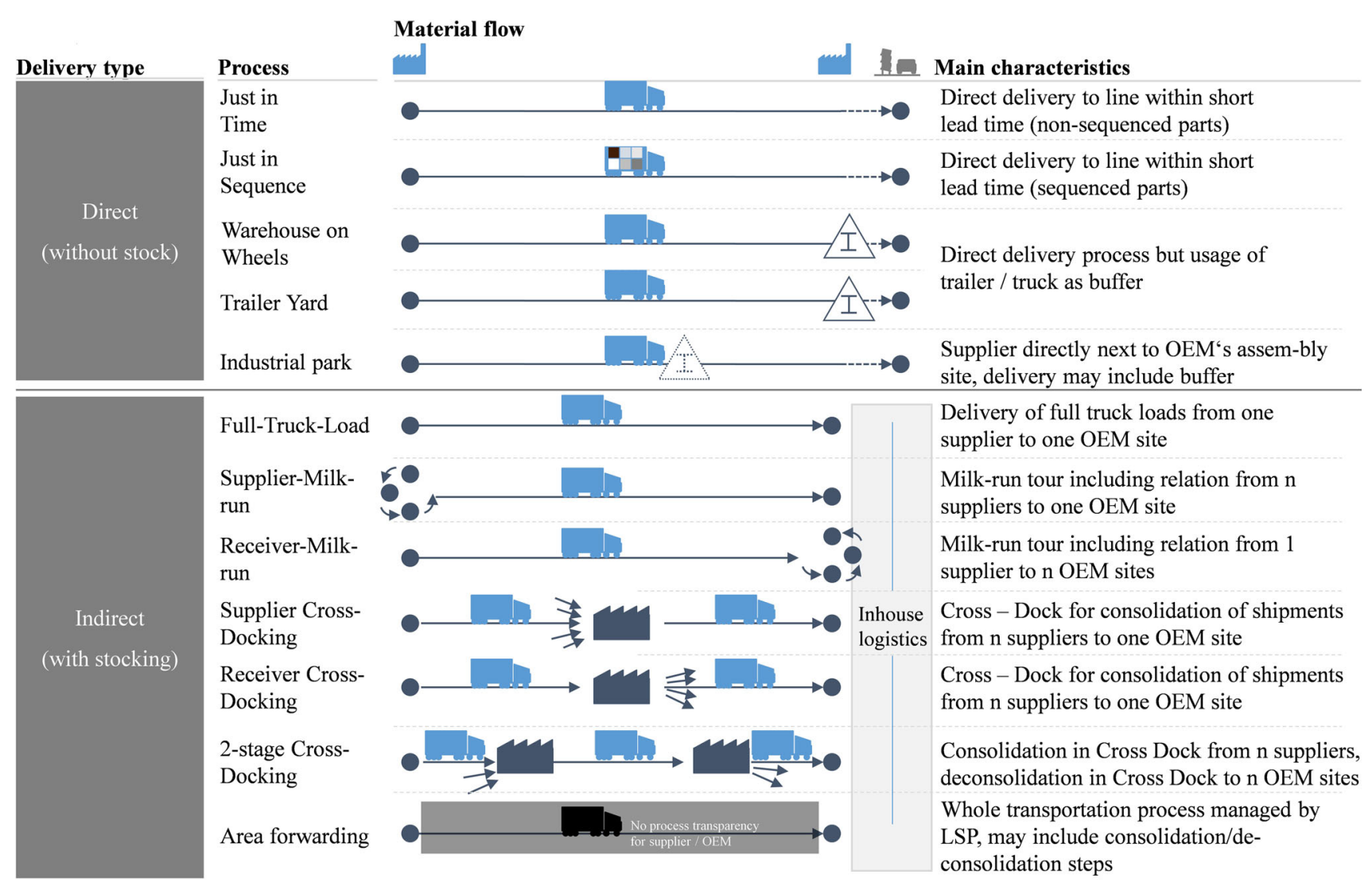

Fig. 4 Logistics reference processes in inbound logistics, using information in [55, 56]

processes. Milk-run processes are also superior in fulfilment of the cost-delivery frequency trade-off.

Nevertheless, those processes did not fully replace former processes, such as AF. Next to the introduction of new processes, the focus of logistics activities shifted, with sequencing and picking activities gaining increasing attention especially in inhouse logistics.

In addition, Fig. 4 points out processes that include a direct delivery to the point-of-use. These processes exclude warehousing and parts stocking on-site, like just-in-time (JiT) or just-in-sequence (JiS) concepts. The concepts of warehouse-on-wheels and trailer yard, which can also be found today, only include the buffering of material during the inbound process, combined with a direct delivery of material to the receiving dock, from which its delivery to the final point-of-use takes place.

Analysing the process variants within inbound logistics justifies the need to cover the whole inbound chain from supplier to point-of-use when designing a holistic PMS; for example, comparing a JiS supply to an AF process, including warehousing and sequencing steps within the inhouse logistics process, requires a perspective of the full process from supplier to the assembly line.
For processes with indirect delivery, a typical in-house logistics process includes at least the reception of goods, truck unloading, warehousing and transportation. In addition, deconsolidation, order picking and sequencing are of increasing importance.

Considering the complexity within the logistics processes in terms of the number of process variants, we suggest a segmentation of the whole process into process modules which can be combined flexibly to represent the implemented processes on-site. Along with this, we suggest a similar modularisation for the logistics PMS in automotive logistics, with each module consisting of standardised performance indicators (Pis) for this respective module (e.g. the one of a direct transportation process) breaking down the overall KPIs of the logistics PMS framework. The idea of modularisation of the inbound processes is highlighted in Fig. 5 (warehouse-on-wheels and trailer yard following the material flow of direct delivery), concluding that all inbound process in Fig. 4 can be designed by either the module of direct transport, milk-run or consolidation/deconsolidation or a combination of those three. All of the modules are backed up with a detailed value stream analysis and information flows for detailed process modelling as base for the PMS definition. 


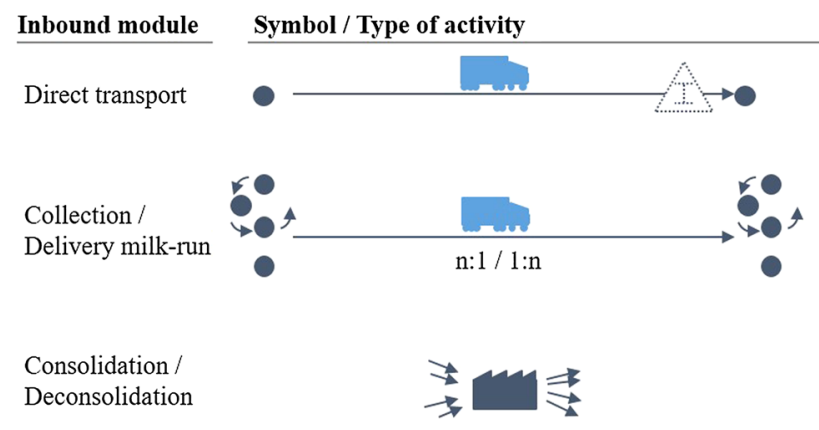

Fig. 5 Suggested modules of the inbound logistics process

This approach has been used throughout the remainder of the paper and detailed in the next sections. By means of the modularisation, we hope to involve managers and team leaders of each step in the supply chain to improve their specific PIs. We assume this principle to be beneficial in terms of limiting PIs for each employee, ensuring flexible applicability and facilitating the link to strategic objectives.

Furthermore, it enables a standardisation of logistics PIs on at least a process step level and therefore can be used for comparison and benchmarking along the whole process of automotive logistics across companies.

\subsection{Overall PMS structure and top-level KPIs}

The suggested PMS structure follows the objectives identified in Sect. 4.2 and the aspect of allowing modularisation of the PMS which is derived from the process perspective. To allow modularisation and aligned PIs on a process level, the following section defines the structure and top-level KPIs.

Reflecting upon the analysis of objectives in automotive logistics, the need for a balanced model, e.g. a balanced score card [19], as a general framework has been emphasised. In each of the dimensions, we suggest to follow what Cagnazzo et al. [18] define as the hierarchical model. To increase specificity, we focused on defining a system of specific KPIs to provide the base for the PIs' definition behind each of the suggested dimensions down to process level.

As dimension of the KPIs, especially the cost and effort related KPIs, we followed the opinion of Gunasekaran et al. [10] that the leading dimension should be the final product delivered to the customer. As the ultimate goal is to deliver a vehicle to the customer, the produced vehicle is our proposed base for all the metrics calculation at top level (e.g. logistics costs per vehicle).

The main dimensions for our framework were efficiency, quality of logistics processes and a lean dimension to combine the objectives of logistic and the demand for transparency on lean logistics principles' fulfilment, resulting from lean ongoing implementations. Logistics efforts and costs were monitored next to resource utilisation within logistics efficiency, and expressed as relative costs by a composite measure [45] to facilitate interpretation.

We suggest naming the quality dimension "perfection" in line with the demand to strive for perfection throughout all the processes found in lean logistics literature. It includes all the logistics quality-related metrics, including material and information flow.

The lean dimension includes the lean principles, namely the flow, takt and pull principles. We see the takt and pull principles' fulfilment adding to an increased flow within logistics-when standing next to each other, the close link between the three principles therefore led us to suggest their integrated monitoring.

In addition, we proposed a dimension of external factors, highlighting aspects which impact upon the primary logistics PIs, but cannot be directly influenced by logistics. One example of external factors is turbulences within the production sequence, requiring resequencing of parts in logistics; a PI measuring stability of production sequence is therefore seen as a key indicator to assess this influence, to facilitate interpretation and comparison of logistics PIs over time, between different sites of a company or across companies.

Figure 6 provides an overview of the proposed dimensions.

As a next step, a line-back analysis was conducted to assign PIs for each of the process modules. By doing so, only PIs were selected which are relevant for each single module. Relevance is decided by the question of whether the single module has an influence on achieving a higher performance in the overarching context of this PI. For example, reflecting the right quantity of parts within one shipment is relevant during the reception of goods where it is suggested as a PI. Line-back, during truck registration,

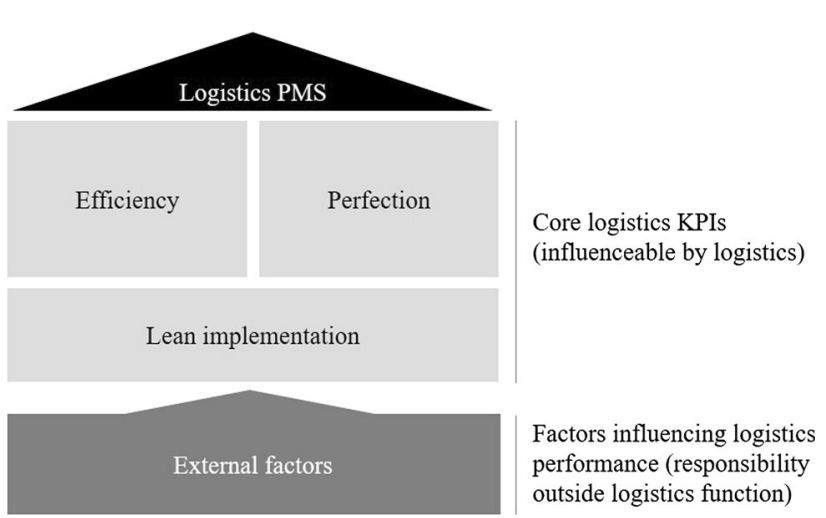

Fig. 6 Structure of the proposed PMS 
the correct quantity of parts within a single shipment can neither be influenced, nor checked: this PI is therefore not monitored for truck registration. On the other hand, following the process further line-back, this PI is again suggested for the supplier. This allows assigning to each process module only PIs that can be influenced and avoids overloading responsibles with PIs.

For the dimension of logistics efficiency, the total set of PMs includes cost KPIs, monitoring of logistics efforts and, to increase applicability in identifying improvement potentials, also a monitoring of capacity utilisation (e.g. transport capacity utilisation, warehouse space utilisation), which is seen as the most important indicator for the identification of improvement options.

Cost monitoring focuses on a holistic cost assessment. The process analysis is therefore used to identify all the costs occurring in each single process step, e.g. monitoring the costs for inbound transportation includes transportation costs. In addition, overhead costs related to transport (e.g. network planning, timetable alignment) need to be included to ensure comparability of the processes.

The requirement of a holistic cost assessment is of increasing importance as, in today's processes, roles are shifting, e.g. from LSPs to OEMs, should area forwarding be replaced by cross-docking. In cross-docking processes, the OEM is responsible for network planning and timetable alignment, a task formerly done by the LSP and included indirectly within the LSP's transportation costs.

The same is applied for "perfection", starting with a definition of the customer's requirement in terms of

- the right part

- at the right time (e.g. the assembly takt where the part is needed reflects the deadline)

- in the right quality

- in the right location

- in the right packaging (the packaging itself, if any, and in the right tray, e.g. car set tray).

Those customer requirements can be transferred lineback through all of the defined process modules.

In addition, not driven by the customer, but especially also in terms of lean logistics process quality assessment, there is the need to assess the fulfilment of process standardisation, as well as the information process. In addition, for "perfection", we suggest PIs to monitor whether the part is delivered using the right process, and whether the process is supported by the correct information (e.g. calloffs). We suggested monitoring the correct process in terms of process compliance with the planned process and, secondly, whether the planned process complies with standard processes within the company.
Correct information in this context includes, e.g. the accuracy of the demand forecast, the quality of labelling or the right information used for call-offs from the line.

Within the lean dimension, the main objective is an increased flow of the material. Therefore, as it is relevant for all process modules, a flow metric for logistics was defined, making waste in terms of waiting time transparent. In addition, the takt and pull principle were evaluated lineback, where takt evaluates whether logistics processes are in line with the manufacturing line's takt (or a multiple thereof) and pull evaluates the call-off principle line-back. Again, PIs were selected by relevance for each logistics module (e.g. no takt or pull can be monitored for truck registration).

Furthermore, we suggest a monitoring of implementation of lean to facilitate the implementation process and to create a PMS applicable from the start of lean implementation by also applying a qualitative questionnaire, e.g. as proposed in [30], as part of the lean dimension for the overall inbound and inhouse logistics process as well as for the overall process from supplier to OEM. By doing so, we link the whole PMS to an implementation monitoring and enable an evaluation of the benefits of lean implementation.

\subsection{Detailed KPI breakdown along the logistics process elements}

As principles for the selection of the relevant PIs, we selected the ones proposed by Gunasekaran et al. [10]: Focusing on

- the main, highly correlating drivers of performance, e.g. cost drivers in terms of the monitoring of logistics costs

- aspects that are quantifiable

- a selected and limited number of KPIs, "less is more"

- the ones that enable improvements and

- the ones which are already available within the company's reporting or can be assessed with limited costs of data collection

Reflecting the last aspect in generic terms is challenging, nevertheless, using our process analysis and basing the development on industry standards, allowed us to select PIs at least in line with what should be available.

In the following, the details on each of the monitored dimensions are provided. Figure 7 summarises the suggested overall KPIs for the automotive logistics chain from supplier to the point-of-use at the customer. As we are focusing on inbound logistics in the following, Fig. 8 highlights the relevant KPIs derived from specifying the overall KPIs from Fig. 7. 


\begin{tabular}{|c|c|c|c|c|c|c|c|c|c|}
\hline Overall & 7 & und & Inhouse & & & & & & \\
\hline \multirow{4}{*}{$\begin{array}{l}\text { Top-level } \\
\text { dimensions }\end{array}$} & \multicolumn{6}{|c|}{ Overall logistics PMS } & & & \\
\hline & \multicolumn{3}{|c|}{ Efficiency } & \multicolumn{3}{|c|}{ Perfection } & \multicolumn{3}{|c|}{ Lean Logistics } \\
\hline & \multicolumn{2}{|r|}{1} & & \multicolumn{2}{|r|}{1} & 7 & \multicolumn{2}{|c|}{\begin{tabular}{l|l} 
\\
\end{tabular}} & $\square$ \\
\hline & $\begin{array}{l}\text { Logistics cost } \\
{[€ / \text { vehicle] }}\end{array}$ & $\begin{array}{l}\text { Logistics effort } \\
{[\mathrm{N} / \mathrm{A}]}\end{array}$ & $\begin{array}{l}\text { Ressource utilisation } \\
{[\%]}\end{array}$ & $\begin{array}{l}\text { Delivery quality } \\
\text { [\%] }\end{array}$ & $\begin{array}{l}\text { Process quality } \\
{[\%]}\end{array}$ & $\begin{array}{l}\text { Information quality } \\
{[\%]}\end{array}$ & $\begin{array}{l}\text { Flow } \\
{[\%]}\end{array}$ & $\begin{array}{l}\text { Pull } \\
{[\%]}\end{array}$ & $\begin{array}{l}\text { Tact } \\
{[\%]}\end{array}$ \\
\hline \multirow[t]{4}{*}{ KPIs } & $\begin{array}{l}\text { Inbound } \\
\text { logistics cost } \\
\text { [ } / \text { vehicle] }\end{array}$ & $\begin{array}{l}\text { Logistics effort } \\
\text { Inbound } \\
\text { [N/A] }\end{array}$ & $\begin{array}{l}\text { Ressource utilisation } \\
\text { Inbound } \\
{[\%]}\end{array}$ & $\begin{array}{l}\text { Delivery quality } \\
\text { Inbound } \\
\text { [\%] }\end{array}$ & $\begin{array}{l}\text { Process quality } \\
\text { Inbound } \\
{[\%]}\end{array}$ & $\begin{array}{l}\text { Information quality } \\
\text { Inbound } \\
\text { [\%] }\end{array}$ & $\begin{array}{l}\text { Flow } \\
\text { Inbound } \\
{[\%]}\end{array}$ & $\begin{array}{l}\text { Pull } \\
\text { Inbound } \\
{[\%]} \\
\end{array}$ & $\begin{array}{l}\text { Tact } \\
\text { Inbound } \\
{[\%]} \\
\end{array}$ \\
\hline & $\begin{array}{l}\text { Inhouse } \\
\text { logistics cost } \\
\text { [€/vehicle] }\end{array}$ & $\begin{array}{l}\text { Logistics effort } \\
\text { Inhouse } \\
{[\mathrm{N} / \mathrm{A}]}\end{array}$ & $\begin{array}{l}\text { Ressource utilisation } \\
\text { Inhouse } \\
{[\%]}\end{array}$ & $\begin{array}{l}\text { Delivery quality } \\
\text { Inhouse } \\
{[\%]}\end{array}$ & $\begin{array}{l}\text { Process quality } \\
\text { Inhouse } \\
{[\%]}\end{array}$ & $\begin{array}{l}\text { Information quality } \\
\text { Inhouse } \\
{[\%]}\end{array}$ & $\begin{array}{l}\text { Flow } \\
\text { Inhouse } \\
{[\%]}\end{array}$ & $\begin{array}{l}\text { Pull } \\
\text { Inhouse } \\
{[\%]}\end{array}$ & $\begin{array}{l}\text { Tact } \\
\text { Inhouse } \\
{[\%]}\end{array}$ \\
\hline & \begin{tabular}{|l} 
Inbound \\
Inventories \\
{$[€ /$ vehicle $]$} \\
\end{tabular} & & & & & & \multirow{2}{*}{\multicolumn{3}{|c|}{$\begin{array}{l}\text { Degree of lean implementation } \\
{[\%]}\end{array}$}} \\
\hline & \begin{tabular}{|l|} 
Inhouse \\
Inventories \\
{$[€ /$ vehicle] }
\end{tabular} & & & & & & & & \\
\hline
\end{tabular}

Fig. 7 Overall KPIs for the proposed PMS

\begin{tabular}{|c|c|c|c|c|c|c|c|c|c|}
\hline Overall & II & und & Inb. Transport & $\ldots$ & Inhouse & 1 & & & \\
\hline \multirow{4}{*}{$\begin{array}{l}\text { Top-level } \\
\text { dimensions }\end{array}$} & \multicolumn{6}{|c|}{ Inbound Logistics PMs } & & & \\
\hline & \multicolumn{3}{|c|}{ Efficiency } & \multicolumn{3}{|c|}{ Perfection } & \multicolumn{3}{|c|}{ Lean Logistics } \\
\hline & \multicolumn{3}{|c|}{1} & \multicolumn{3}{|c|}{1} & \multicolumn{2}{|r|}{1} & a \\
\hline & $\begin{array}{l}\text { Inbound } \\
\text { logistics cost } \\
{[€ / \text { vehicle] }}\end{array}$ & $\begin{array}{l}\text { Logistics effort } \\
\text { Inbound } \\
\text { [N/A] }\end{array}$ & $\begin{array}{l}\text { Ressource utilisation } \\
\text { Inbound } \\
{[\%]}\end{array}$ & \begin{tabular}{|l}
$\begin{array}{l}\text { Delivery quality } \\
\text { [\%] }\end{array}$ \\
\end{tabular} & \begin{tabular}{|l|} 
Process quality \\
[\%]
\end{tabular} & $\begin{array}{l}\text { Information quality } \\
\text { [\%] }\end{array}$ & $\begin{array}{l}\text { Flow } \\
{[\%]}\end{array}$ & $\begin{array}{l}\text { Pull } \\
{[\%]}\end{array}$ & $\begin{array}{l}\text { Tact } \\
{[\%]}\end{array}$ \\
\hline \multirow[t]{7}{*}{ KPIs } & $\begin{array}{l}\text { Transport- } \\
\text { ation cost } \\
{[E / \text { vehicle }]} \\
\end{array}$ & $\begin{array}{l}\text { Transport } \\
\text { service } \\
\text { [to*km/veh.] }\end{array}$ & $\begin{array}{l}\text { Transport capacity } \\
\text { utilisation Inbound } \\
\text { [\%] }\end{array}$ & \multirow{2}{*}{$\begin{array}{l}\text { Delivery date } \\
\text { and quantity } \\
\text { reliability } \\
\text { Inbound } \\
{[\%]}\end{array}$} & \multirow{2}{*}{$\begin{array}{l}\text { Process con- } \\
\text { formity with } \\
\text { standard } \\
\text { processes } \\
{[\%]}\end{array}$} & $\begin{array}{l}\text { Stability of call-off } \\
\text { orders } \\
{[\%]}\end{array}$ & $\begin{array}{l}\text { Flow } \\
\text { Inbound } \\
\text { [\%] }\end{array}$ & \begin{tabular}{|l|} 
Pull \\
Inbound \\
{$[\%]$} \\
\end{tabular} & $\begin{array}{l}\text { Tact } \\
\text { Inbound } \\
{[\%]} \\
\end{array}$ \\
\hline & \multirow{2}{*}{$\begin{array}{l}\text { Consolida- } \\
\text { tion cost } \\
{[€ / \text { vehicle] }} \\
\end{array}$} & \multirow{2}{*}{$\begin{array}{l}\text { Transported } \\
\text { load } \\
\text { [to/veh.] }\end{array}$} & \multirow{2}{*}{\begin{tabular}{|l|} 
Space utilisation \\
Inbound facilities \\
[\%] \\
\end{tabular}} & & & \multirow{2}{*}{$\begin{array}{l}\text { Quality of transport } \\
\text { documents } \\
{[\%]}\end{array}$} & \multirow{3}{*}{$\begin{array}{l}\text { Through } \\
\text { put time } \\
\text { Transpo } \\
\text { rt [hrs] }\end{array}$} & & \\
\hline & & & & \multirow{3}{*}{$\begin{array}{l}\begin{array}{l}\text { Packaging } \\
\text { conformity and } \\
\text { quality Inbound } \\
{[\%]}\end{array} \\
\end{array}$} & \multirow{3}{*}{\begin{tabular}{|l|} 
Process \\
conformity \\
with planned \\
processes \\
{$[\%]$} \\
\end{tabular}} & & & & \\
\hline & \multirow{2}{*}{$\begin{array}{l}\text { Overhead } \\
\text { cost } \\
{[€ / \text { vehicle }]}\end{array}$} & $\begin{array}{l}\text { Transported } \\
\text { distances }\end{array}$ & \multirow{4}{*}{$\begin{array}{l}\text { Dock capacity } \\
\text { utilization } \\
\text { Inbound facilities } \\
{[\%]}\end{array}$} & & & \multirow{2}{*}{\begin{tabular}{|l|} 
Quality of remote \\
transmission data \\
{$[\%]$} \\
\end{tabular}} & & & \\
\hline & & [km/veh.] & & & & & \multirow{2}{*}{\begin{tabular}{|l|} 
Through \\
put time \\
Deconso \\
lidation \\
[hrs] \\
\end{tabular}} & & \\
\hline & $\begin{array}{l}\text { Inbound } \\
\text { Inventories } \\
{[€ / \text { vehicle }]}\end{array}$ & $\begin{array}{l}\text { Number of } \\
\text { handlings } \\
\text { Inbound } \\
\text { [\#/ vehicle] }\end{array}$ & & \multirow[t]{2}{*}{$\begin{array}{l}\text { Parts quality } \\
\text { Inbound } \\
\text { [\%] }\end{array}$} & \multirow[t]{2}{*}{$\begin{array}{l}\text { Number of } \\
\text { exception } \\
\text { handlings } \\
\text { [\#/ vehicle] }\end{array}$} & \multirow[t]{2}{*}{$\begin{array}{l}\text { Quality of labeling } \\
\text { [\%] }\end{array}$} & & & \\
\hline & & $\begin{array}{l}\text { Average } \\
\text { handlings per } \\
\text { shipment } \\
\text { [\#/ } \\
\text { shipment] }\end{array}$ & & & & & \multicolumn{3}{|c|}{$\begin{array}{l}\text { Degree of lean implementation } \\
\text { inbound } \\
{[\%]}\end{array}$} \\
\hline
\end{tabular}

Fig. 8 KPI breakdown to inbound logistics

These KPIs provide the base for the PIs' definition for the inbound process modules. This logic is highlighted in Fig. 9 for the direct transport module, considering only PIs which can be influenced within this module.

The following section summarises the reasoning for the (K)PI selection. To monitor efficiency, all the relevant costs occurring within each process step are monitored, e.g. in inbound logistics transportation costs, consolidation costs and overhead costs (e.g. transportation network planning). Furthermore, we suggest including a monitoring of inventories to also cover stocking and buffering functions which are moved from inside the plant to an inbound 


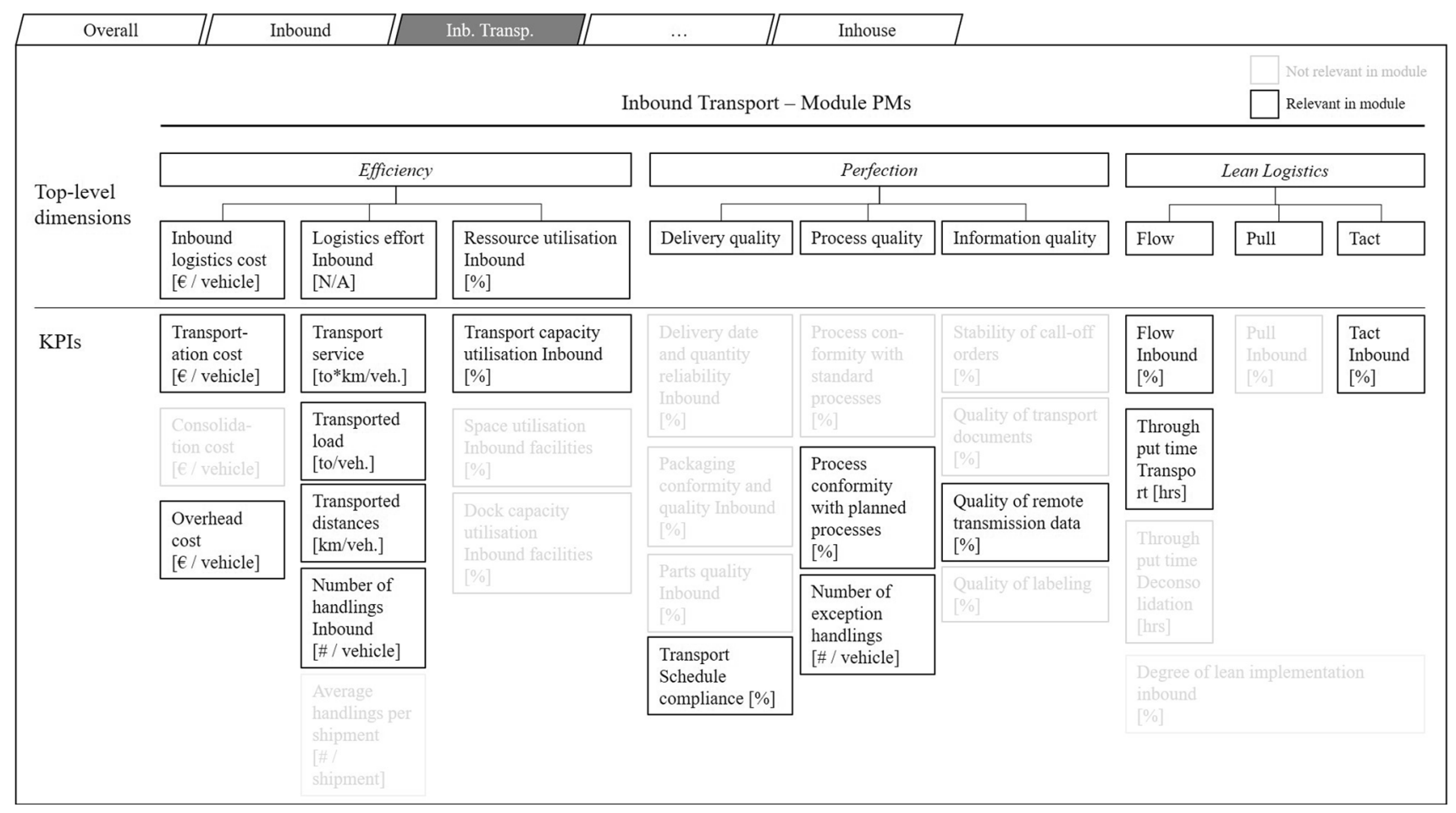

Fig. 9 PMs for transportation module inbound logistics for 1:1 transportation

function (e.g. by applying warehouse-on-wheels concepts with goods receiving only upon unloading). To enable the interpretation of data, next to cost monitoring, the main cost drivers from a logistics effort perspective are linked, e.g. transportation service incl. volume and distance, handled units in consolidation functions. The utilisation of transport and dock capacity is suggested as a KPI which facilitates improvements, e.g. transport utilisation below a certain threshold can be used as a transparent trigger for alerts, whereas transportation volume is more difficult to interpret. Furthermore, regarding the logistics effort we include the number of handlings per shipment being an indicator of complexity of process and an enabler for improvements.

Within "perfection", delivery quality monitors the effectiveness from a customer's perspective, focusing on material flow and the question as to whether logistics is supplying what needs to be supplied. Information quality focuses on the relevant information for supporting the inbound logistics process, e.g. the stability of call-offs from suppliers (which can be seen as prerequisite for on-time delivery in inbound logistics), or the quality of transportation documents and labellings (which supports the inbound logistics process and, if incorrect, leads to an increased workload in goods receiving).

In addition, for an interpretation of improvement potentials, the knowledge of whether the processes comply with the planned ones is also required. In industry, this has two dimensions-firstly, the question of whether processes come alive in the way they are planned, and secondly, the aspect of whether the processes that are planned are in line with the standard processes developed within a company and supply chain. Especially in automotive logistics, characterised by a large number of manufacturing sites per company, the question arises as to whether the standardised process can be, and is, followed at all the sites or whether there are specifics on-site which hinder the implementation of standard processes and the specificity of the standardswe therefore proposed splitting this aspect into two metrics.

Within the lean dimension, we proposed a flow metric for logistics to measure the material flow in terms of logistically added value and required time. For this, the flow metric is based on the fact that the logistics processes, if designed correctly, only include activities really required to fulfil customer needs, e.g. bridging the distance between the supplier and the manufacturer, as well as picking and sequencing. They can therefore be seen as logistics "added value" to the fulfilment of the customer (manufacturing line) needs. From the OEMs point of view, an increased margin can be gained, for instance, by low-cost country sourcing which is only possible due to logistics. Activities within logistics can therefore be seen as adding value while others, e.g. storage, additional transport or quality issues, are seen as waste. To assess the share of added value time versus waste, we proposed the transferral of the concept of a flow metric from production to logistics. 
For inbound logistics, this leads to the definition that bridging the distance between supplier and manufacturing plant can be seen as adding value as long as the transport (distance supplier to OEM plant) is carried out with efficient velocity, (e.g. $80 \mathrm{~km}$ per hour as a maximum for truck transport in most countries in the EU). All the other time required for the inbound processes are losses which increase the lead time and should be avoided when aiming for reduced stock levels. Due to this, and for comparability reasons, we proposed this standardised flow metric as a KPI. The definition for the example of an inbound transportation flow metric is provided in the appendix. Next to flow, the evaluation of lean also considers the takt principle being transferred to logistics, as well as the pull principle being implemented for material demand steering and control.

As indicated in Fig. 8, also the monitoring of the degree of lean implementation using the qualitative questionnaire approach is not suggested on the process module level. Due to the reasoning that the majority of lean logistics principles are defined for a value stream rather than a single process step, and therefore can only be evaluated in case of linked modules, an evaluation is only suggested down to the inbound logistics process level.

As external factors in the context of inbound logistics, we proposed to monitor, e.g. the average distance to suppliers, handled part numbers on-site, number of suppliers, production sequence accuracy. Such PIs can assist in the comparison of the inbound logistics cost between manufacturing sites in different locations, for example.

\subsection{Definition of KPIs using the developed KPI definition sheet}

As found during the literature review, the benefit of standardised KPI definitions is unquestioned. We proposed a standardised KPI definition sheet for all the included metrics to ensure alignment with the interpretation of metrics among all parties. Objectives of the definition sheet for each metric are to ensure the same application of the (K)PIs throughout the company and supply chain, as well as the transparency of data sources, the calculation and the interaction to other metrics. Thanks to this effort in metrics definition, we hope to address the current hurdle encountered in many companies that cross-site comparisons and identification of best practices are hindered by the nonstandardised use of (K)PIs [57]. We provided an example of a KPI definition sheet for the flow metric of inbound logistics transport function in the appendix (see Fig. 17). Due to length limitations, not all the definition sheets can be included in this paper. ${ }^{2}$

\footnotetext{
${ }^{2}$ Additional definition sheets can be requested from the authors.
}

At this stage, it must be remembered that, beyond a detailed (K)PI definition, standardisation also has to include data sources, measurement points and reporting channels for a fully comparable PMS. Especially in logistics, researchers currently report on the limited standardisation of IT systems [58].

\subsection{Summary of the proposed PMS}

As a result of the development phase we propose a PMS for automotive logistics, which is broken down from the logistics objectives to a process module level.

The definition of logistics objectives accounts for the multi-dimensional objectives of today's logistics environment and integrates the lean logistics principles next to classical logistics objectives. Breaking down the resulting KPIs into PIs ensures their systematic linkage-from the strategic down to the operational level.

In addition, the breakdown along process modules ensures the specificity needed to enable continuous improvement. Standardisation is enabled by the modular approach, allowing to combine standardised PIs of the relevant process modules to reflect the whole logistics process while maintaining comparability of the PIs of each module. The modular approach therefore accounts for the complex, differentiated logistics process landscape found in industry today and facilitates standardisation as far as possible.

Figure 10 summarises the resulting PMS and highlights the main aspects of the structure. For examples of the metrics included, please refer to Figs. 7, 8, 9 presented before.

\section{Evaluation}

The following section evaluates the proposed PMS approach using a case study at a German OEM covering a one-year process of modification and implementation of the PMS (step 6 in the overall process) and its evaluation at two manufacturing sites. The authors were involved in the PMS modification to the company, the implementation and, based on the findings, led the evaluation phase.

The following provides a short introduction to the focus company and the selected sites for the PMS application. After that, a brief summary of the modification of the proposed PMS and the implementation is provided (see step 6 of the PMS development process). Section 5.3 describes the evaluation phase in detail.

\subsection{Case-study introduction}

We selected a large German OEM as focal company for the evaluation. As described before, selecting an OEM offers the opportunity for a broad evaluation of the applicability 


\section{Proposed PMS for automotive logistics}

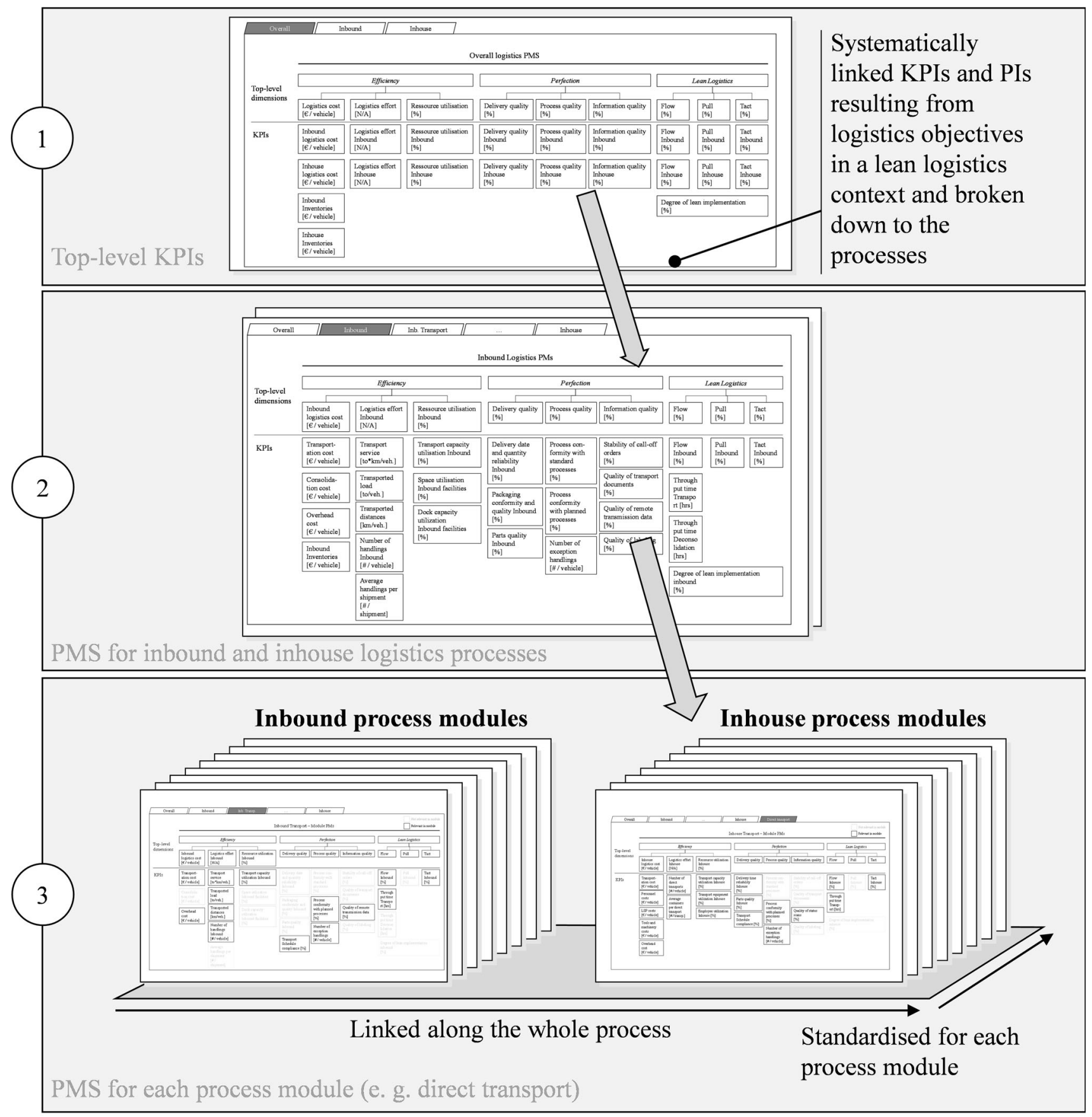

Continuous improvement, enabled by process oriented PIs derived from the logistics ${ }^{6}$ objectives

Fig. 10 Summary of the proposed PMS 
of the PMS within an environment with a high process complexity.

We selected two manufacturing sites of the OEM. One of the two selected sites can be considered one of the largest, high-volume assembly sites of the company, the other represented the smaller plants.

The range of products assembled at the two sites range from mid-class to luxury, premium vehicles. In total, five different models are produced within the two plants. The plants have implemented the latest manufacturing and logistics concepts throughout recent years. Those concepts can be seen as applying lean logistics principles.

Both plants, besides using the same standardised logistics concept, can be described as differing in terms of their operational processes due to significantly different volumes and the set-ups of production facilities. Nevertheless, commonalities do exist. Both plants handle their in-house logistics partially by using an external warehouse, requiring transport to the assembly site after an external goods receiving, warehousing and some de-consolidation, picking and sequencing steps. In addition, depending on the specific part numbers, those processes can also be handled internally on-site.

In terms of the regional dimensions, the whole supplier base is covered, which mainly includes European suppliers. Therefore, in terms of regionality, the case study can be described as European according to the supplier locations. The main transport mode is road transportation, besides supplies from the company's other production sites, which are partially done via railway.

The implementation and evaluation of the PMS took place within the logistics function of both sites, including the inbound and in-house logistic responsibilities. We covered the functions of material planning, material handling, logistics planning, information logistics and logistics controlling in detail. The whole process, from the suppliers to the point-of-use, was therefore covered.

Our findings from the first interviews in respect of the current use of PMS at the two sites confirmed the experience of other researchers, e.g. [49] regarding PMS application in industry today. We found a decentralised reporting of single performance indicators without a connection to a holistic and structured PMS. Correlations and links between metrics were not highlighted, nor were they systematically analysed. The IT infrastructure did not support the updating and evaluation of reports, leading to a huge manual workload in report preparation and metric evaluation. The redesigning of KPIs, after implementation of the new lean logistics concepts, has also not yet taken place.

On the other hand, our observations also confirmed the research of Lohmann et al. [49] that typically some performance indicators and standardised reports are already in place. In addition, we ascertained that some top-level KPIs are applied across the company's sites. As the two sites show similarities to that which other researchers typically find in industry, we assume them to be a good research base.

\subsection{Company-specific PMS adjustment and evaluation of the PMS approach}

For company-specific adjustments to the proposed PMS framework, first of all document analysis, workshops and interviews within the two sites were conducted. We mainly focused on the documentation of standard or reference processes within logistics, which are available at central departments.

By so doing, we aimed to provide an overview of the company-wide objectives shared throughout our casestudy company. The analysis confirmed our analysis of logistics objectives within automotive logistics (Sect. 4.2). Furthermore, we were able to identify some company-specific objectives, e.g. employer branding related targets. Those objectives were not broken down to a functional, logistics level with more specific objectives, but applied throughout the company. In the following, we therefore focused on the objectives specifically attributed to logistics.

After this alignment on the objectives of logistics, we focused on the modification of the PMS with its proposed KPIs and PIs. As this step was also used as an evaluation step, and not just as a modification step, we conducted a series of open workshops and interviews.

A first workshop was conducted with the intention of understanding the required (K)PIs that managers and logistics experts on-site require to steer their business. During these workshops, only a brief overview of the proposed PMS was given, without a detailed explanation of the included PIs and the modularisation approach. Thereafter, currently applied (K)PIs, and additional ones required to monitor, control and improve logistics on-site, were collected along the logistics process. The workshops also showed that the additional metrics differ between the two sites, confirming that they are not generic PIs, but sitespecific.

Summarising the findings, we concluded that the current set of metrics which are used within the two sites only show a limited coverage of what should be measured to effectively improve logistics processes. In addition, by consolidating the results of the workshops, we found that most of the metrics which were deemed necessary to monitor, control and improve logistics were covered in our developed PMS approach. An additional set of metrics was identified which covered aspects that the experts within the workshops judged to be site-specific. 


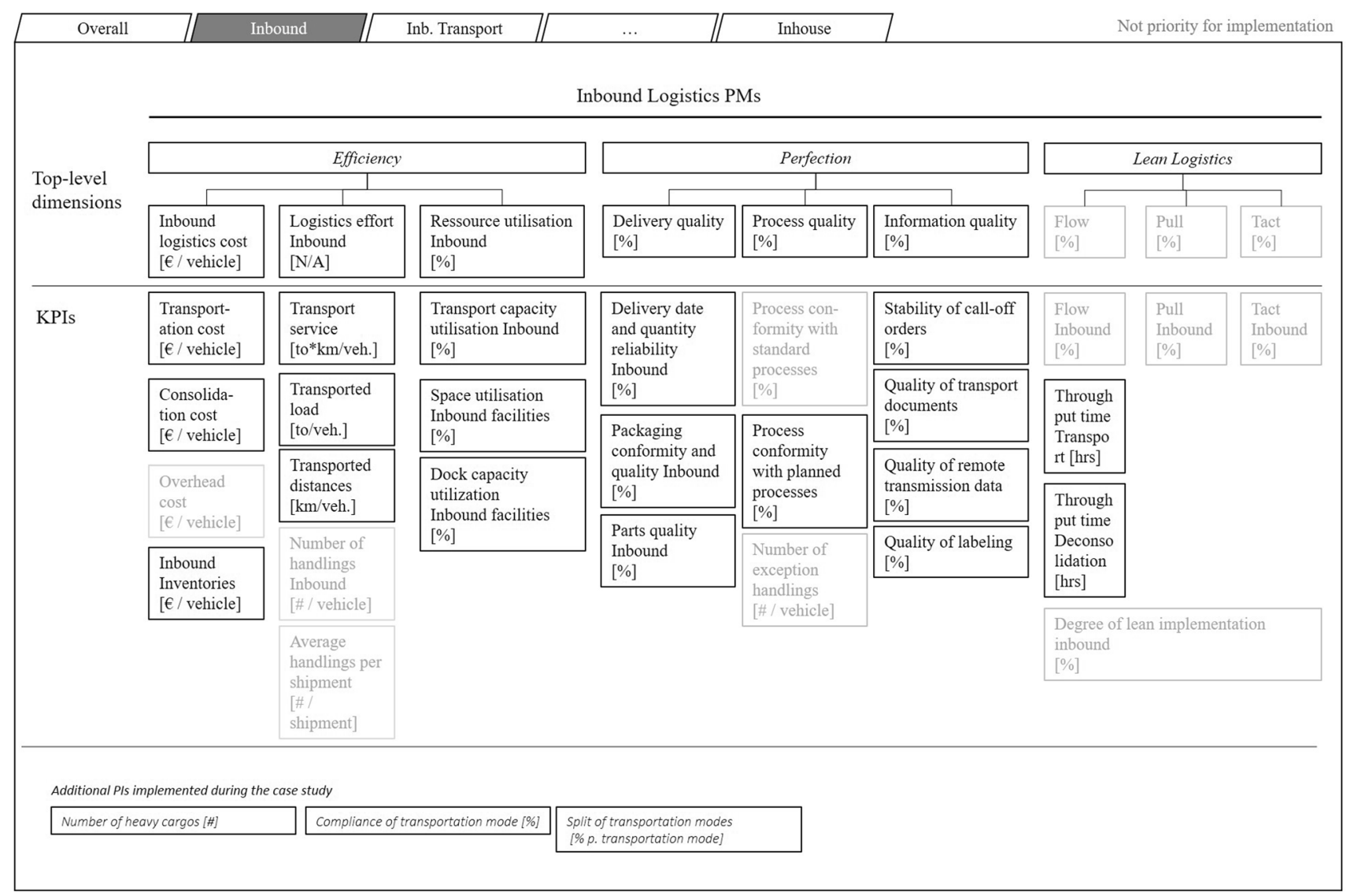

Fig. 11 PMS for inbound logistics from implementation during the case study

Additional analysis was carried out to analyse the processes on-site and compare the results to the proposed modules of our logistics PMS. Findings indicated that, by combining our proposed process modules, all the relevant steps within the logistics process could be monitored.

The findings from process analysis, interviews and workshops were consolidated and the additional metrics were added to the proposed framework. In addition, we consolidated metrics that were named differently by different site representatives but were the same metric, which again shows a lack in overall standardisation of PIs. In a second round of workshops, the consolidated PMS was presented and confirmed by the logistics experts and managers.

Summarising the modification and evaluation of the overall PMS framework, we concluded that all the main aspects along the process were covered within our approach. In addition, we benefited from the flexibility gained by our modularisation approach, which allowed us to fit the PMS to the processes within the focus sites and company. Metrics which are currently available on-site, but not yet considered within our system, could furthermore be flexibly added to the proposed dimensions of the PMS. Figure 11 summarises as a selected example the PMS for inbound logistics which was decided for implementation.
The figure highlights the limited number of additional PIs and some metrics that were found not in focus yet and therefore not priority for realisation. Those metrics especially cover the top-level metrics reflecting the lean principles. Whereas pull and tact are not yet in focus in the operative logistics management, regarding the flow metric the experts judged it relevant, but the first step of consolidating the throughput times and capturing them automatically as basis for the flow calculation was set as priority.

We concluded that the framework approach helped to increase the acceptance within the company and left room for focus areas which were typically site-specific. At the same time, the detailed scope of the suggested PMS actually helped with applying it in the automotive industry. This finding is in line with previous research which highlighted the importance of shared standardised metrics on the one hand [49], but allowed for additional, specific metrics on the other.

\subsection{Evaluation of the PMS in daily application}

After the final alignment, the proposed PMS was implemented into an IT system with an automated dashboard as a reporting tool. This allows KPIs to be frequently updated, 
e.g. on a weekly or, in the case of critical KPIs, on daily basis, to provide logistics departments with the latest information.

A first direct benefit is the significantly reduced workload due to the automated updating of (K)PIs and their consolidation. We concluded from our case study that regarding the suggested (K)PIs most of the data are available for automatic reporting. The approach of a process analysis including the information flow and measurement points as base for reported data is therefore well suited for deriving a PMS in automotive logistics. The aspect of selecting (K)PIs within a PMS, for which data is already available, mainly held true.

Furthermore, we evaluated the benefit of the PMS and the integrated PIs, with a focus on their design, to identify continuous improvement potentials. In the following, an example of the utilisation of a goods receiving function is demonstrated. By selecting this aspect, we focused on the link between inbound logistics and in-house logistics to also demonstrate the logistics process perspective at this interface.

Figure 12 shows the PM of truck arrivals on sites which can be seen as an operational PI. The created transparency highlights improvement potential in levelling truck arrivals, a main driver of the workload in trucks registration and goods receiving. The calculated average arrivals during one working week is $40 \%$ of the peak load, in addition, significant deviations in utilisation are highlighted, also within shifts.

Analysing this PI further on a receiving dock level also shows volatility at the receiving dock level (Fig. 13), with an average utilisation amounting to $\sim 35 \%$ of the peak volumes.

Considering that staffing levels are typically not set for covering peaks, this leads to the hypothesis that truck waiting-time increases in peak periods, a fact that is seen in the increased truck-throughput time (waiting + unloading time), Fig. 14.

Combining Figs. 12 and 13, we concluded that, currently, the truck arrivals on-site, and at each receiving dock, show further potential for levelling the workload, an enabler for optimising costs in truck registration, receiving dock and waiting-time charges for LSPs.

Linking these findings to potentials for increased target fulfilment in logistics led to the conclusion that, in inbound logistics costs, there is the potential to reduce waiting-time charges (covered in transportation cost) by levelling the truck arrivals. In addition, within in-house logistics, the potential to optimise staffing levels at truck registration, as well as goods receiving, can be identified, leading to an impact on in-house logistics cost.

Applying general thinking within lean literature, reducing the volatility in load, especially high peak-overloads, will also lead to a reduction in mistakes in the

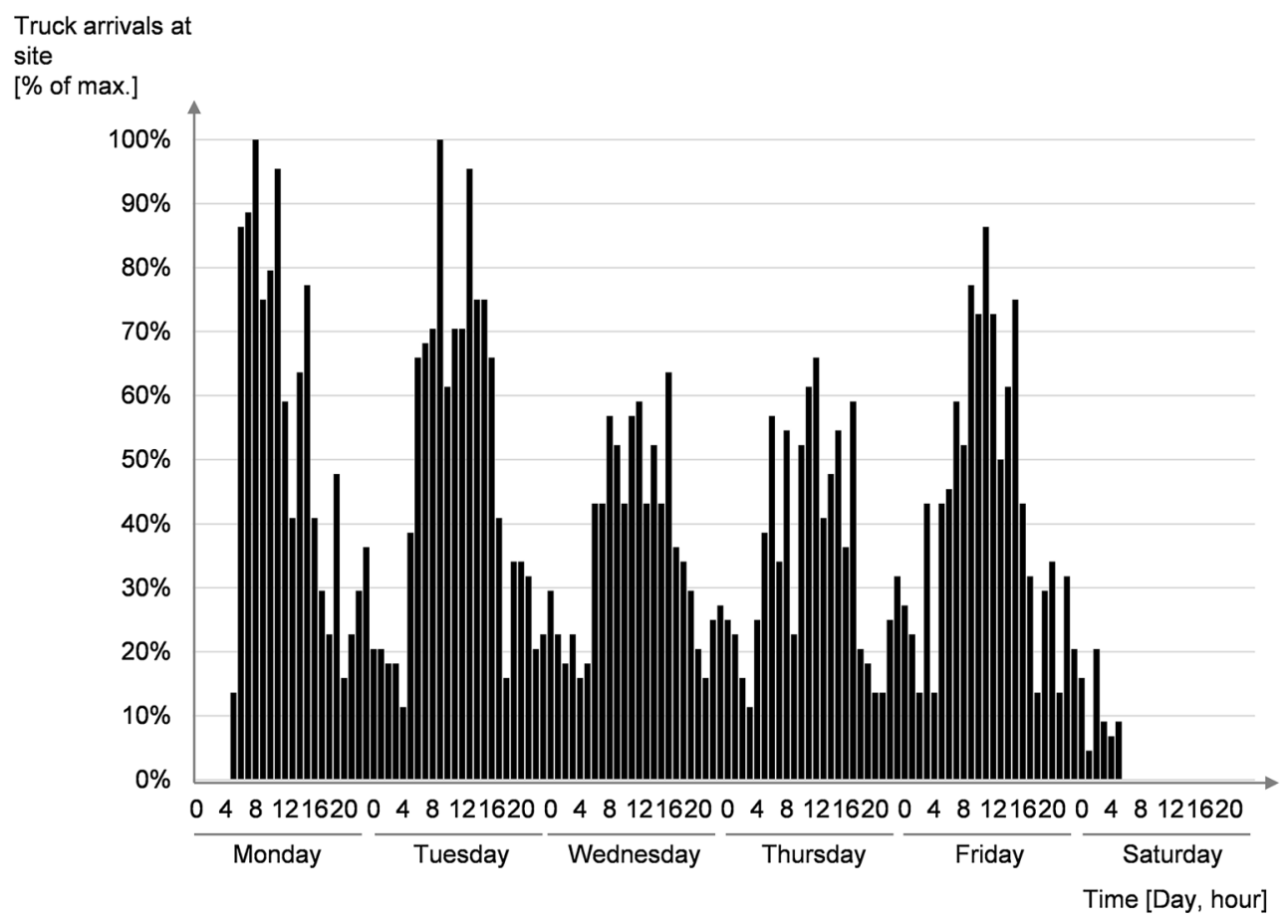

Fig. 12 Truck arrival at site during one selected week 


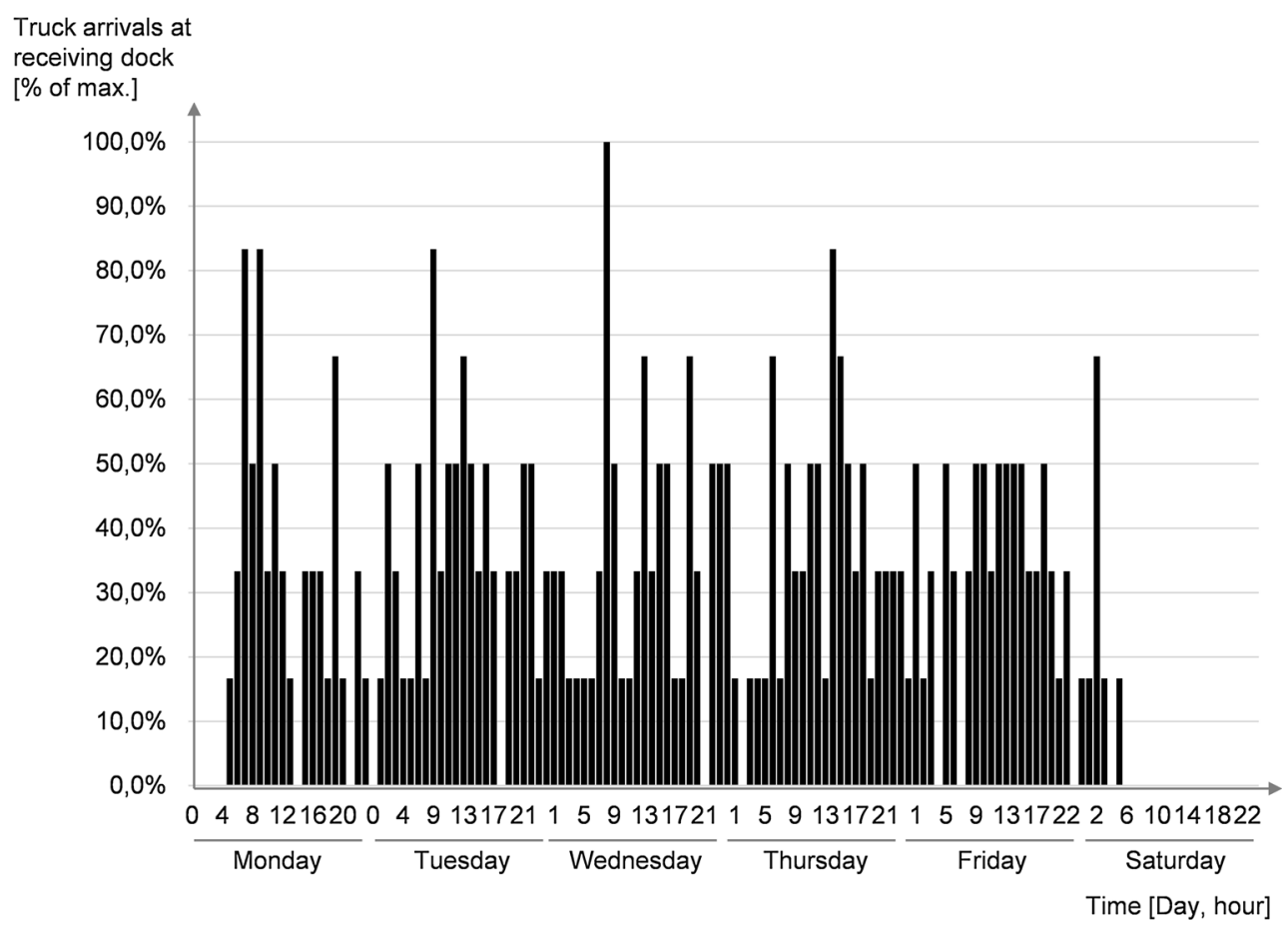

Fig. 13 Truck arrival at one receiving dock during one week

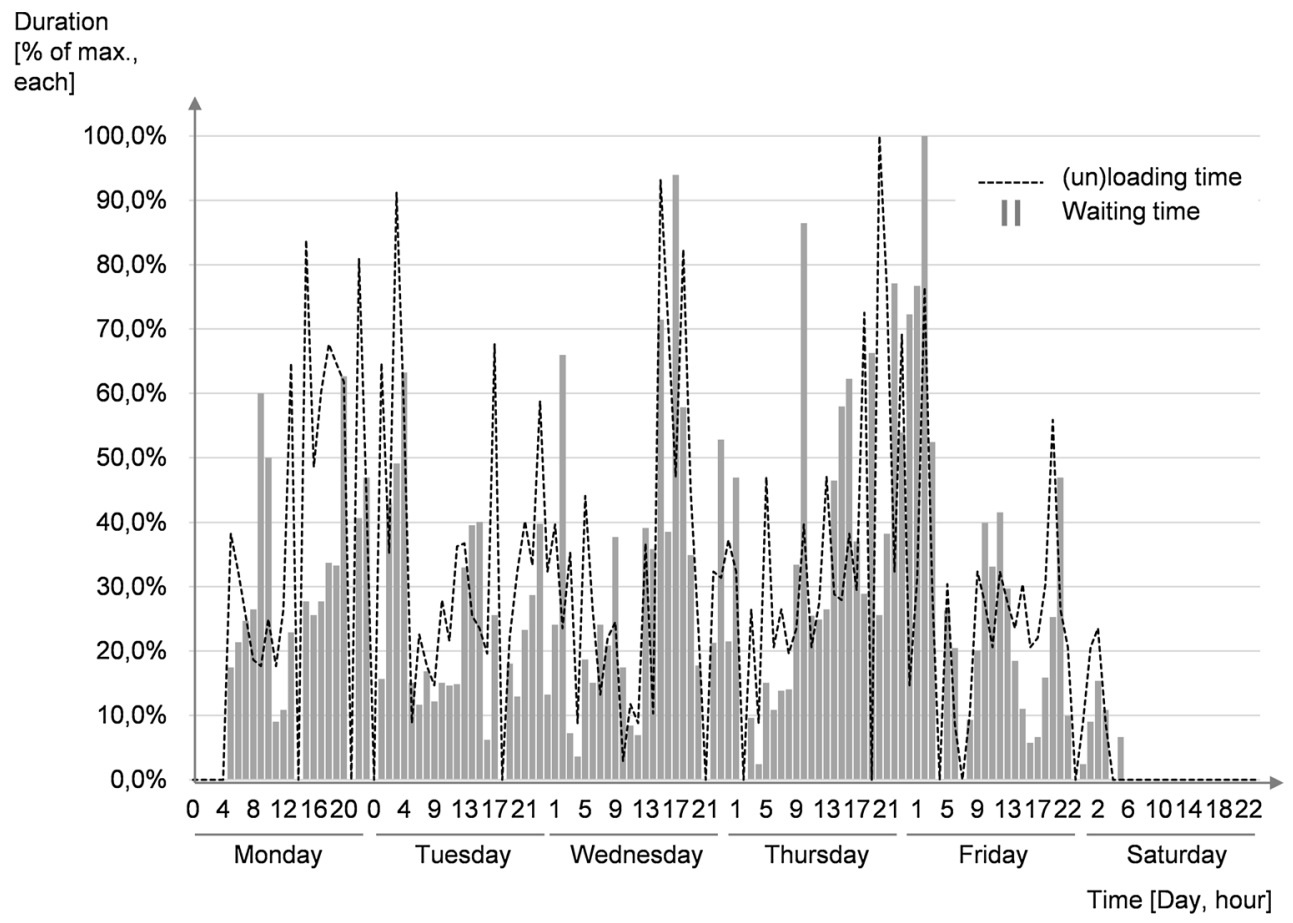

Fig. 14 Waiting and (un)loading time during one week at a selected dock

involved functions as non-levelled operations are a source of quality issues. The objective of increased flow, and therefore the increased lean degree of logistics on-site, is also positively affected.

\subsection{Evaluation summary}

Our evaluation highlighted the general applicability of the proposed PMS. A case study at two manufacturing sites of 
Fig. 15 Summary of evaluation results
(1) Evaluation of proposed logistics objectives (section 5.2) (2) Evaluation of the proposed
logistics process modulari-
zation (section 5.2)

\section{Results}

- Proposed logistics objectives (section 4.2) confirmed in case study context

- Company specific objectives identified that are not logistics specific (e.g. top-employer)

- Current processes could be analysed using the proposed logistics process modules

- Overall logistics processes in modular structure derived as base for the PMS implementation

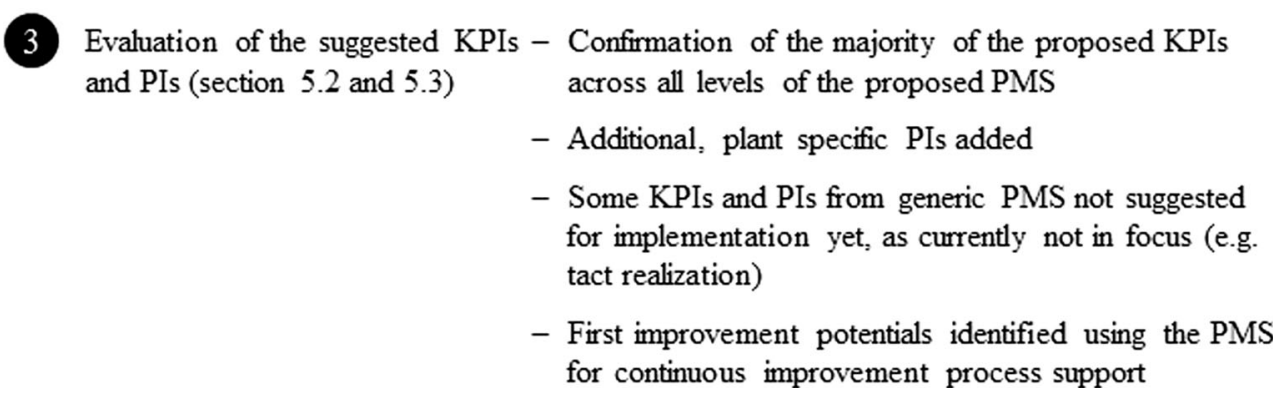

a German automotive OEM was used to demonstrate the modification and the application of the PMS in an industry context. Furthermore, first results from the PI analysis were able to demonstrate continuous improvement potentials towards an increased target fulfilment in the areas of efficiency, perfection and lean.

We found in particular that the flexible design of the system, with its modular approach, and the selected dimensions, which leave room for adding company or sitespecific PIs, showed its applicability. This aspect was highlighted during the application at two different sites. While both sites are managed within the same company and sharing the same objectives, they are still facing different operational problems and site specifics, demanding for different additional metrics on an operational level. All of them could be integrated into the proposed system.

Although the PMS is currently already implemented into a monitoring cockpit, further research is needed on the aspects of how to actually design a logistics PMS cockpit and which intelligence to integrate into the system for supporting the users as much as possible, e.g. by making the IT tools capable of alerting the user in case of deviations from desired target values, or using learning algorithms to automatically highlight selected PMs.

Figure 15 summarises our evaluation results. We conclude from the experiences gained during the case study that the proposed PMS is able to fulfil the design criteria defined from the current gaps in the literature and the automotive logistics environment (see Fig. 3).
Nevertheless, considering the disadvantages of the casestudy approach leads us to demand a broader application of the proposed PMS in industry to demonstrate its applicability beyond the focal company of our case study.

\section{Conclusion}

Our research focuses on the development of a PMS applicable in the automotive logistics chain. The starting point was the central research question of our paper, how $a$ PMS suitable for the automotive logistics environment should be designed. The findings regarding the questions addressed throughout the paper (Fig. 1) are summarised in Fig. 16. The following section highlights the main contribution of our research to the body of knowledge in performance measurement in the automotive industry in the context of lean logistics.

As highlighted during the literature review, academic research, as well as industry, is currently lacking PMS which are applicable in the automotive logistics environment and appropriately designed according to latest research recommendations. The systems proposed in the literature today lack specificity, while the systems in industry lack standardisation and structure. Applied reporting systems often miss a system perspective, including linked PMs, as well as a supply chain perspective. The majority of them are currently internally focused, with metrics not going beyond a single manufacturing site. 
Fig. 16 Summary of our research results

\begin{tabular}{|c|c|}
\hline Questions adressed by our research & Conclusions \\
\hline $\begin{array}{l}\text { How applicable are current PMS } \\
\text { in literature considering the } \\
\text { design criteria and requirements } \\
\text { from the current automotive } \\
\text { logistics environment? }\end{array}$ & $\begin{array}{l}\text { - Literature currently lacks a PMS specific enough for } \\
\text { an application in automotive logistics processes } \\
\text { - Furthermore, systems in literature do not integrate } \\
\text { aspects resulting from lean logistics concept, today's } \\
\text { industry standard. Furthermore, data availability, an } \\
\text { enabler for automized reporting is not considered yet }\end{array}$ \\
\hline $\begin{array}{l}\text { How should a suitable PMS for } \\
\text { today's automotive logistics } \\
\text { environment be designed? }\end{array}$ & $\begin{array}{l}\text { - We propose a modular PMS for the automotive logistics } \\
\text { chain, using } \\
\text { - a process perspective integrating material and } \\
\text { information flow processes, } \\
\text { - integrating lean logistics objectives and } \\
\text { principles and define } \\
\text { - a modular structure of the overall PMS to ensure } \\
\text { standardization across the supply chain and a } \\
\text { - systematic KPI breakdown, allowing targeted } \\
\text { continuous improvement support }\end{array}$ \\
\hline
\end{tabular}

C Is the PMS developed in (B) suitable in an industry context and which changes are required for its implementation?
- A case study based evaluation demonstrates the applicability of the PMS with limited adjustments to modify the approach to a specific OEM
Furthermore, they often involve high manual workload for data analysis and KPI evaluation.

Our research work proposes a modular PMS for the automotive logistics chain to overcome the aforementioned gaps and to answer the research question. We structure our PMS along the logistics objectives which provide a frame for the PMS development. A process perspective is integrated into the PMS to increase specificity and facilitate continuous improvement initiatives. In addition, by integrating the lean logistics principles, an alignment of our approach with the latest developments in logistics concepts in industry is achieved and lean implementation is supported applying a consistent PMS.

To ensure standardisation and, at the same time, the flexibility to adapt the PMS to specific logistics processes within a specific company or even manufacturing site, we proposed a new, modular set-up of the PMS, breaking down the identified logistics objectives to each process step within the logistics chain, from a supplier to the customer. The proposed modular PMS can be configured in line with the processes, resulting in a consistent PMS for the whole logistics chain and offering the potential for a supplychain-wide roll-out while, at the same time, covering sitespecific processes in a standardised way.

In addition, the comparability of PMs in terms of benchmarking is ensured along the logistics process steps, as well as in the overarching PMS. Ensuring operational
PIs are systematically linked in a cause-and-effect relationship, e.g. resource utilisation PIs in line with the main cost drivers, further enables continuous improvement. In addition, by first providing a framework for the overall PMS, the option to add own PIs for each step is kept, which is seen in the literature as key to achieve an enabling, motivating PMS.

With our selected approach, we hoped to deliver a system applicable in the automotive context, specific enough for practitioners to implement the approach, whilst also allowing the flexibility to adapt it to the company's context.

The evaluation of the proposed approach at two manufacturing sites of a German automotive OEM demonstrated the applicability of the proposed framework. The objectives identified in the literature could be seen in line with the set of objectives followed within the logistics function of our case-study company. The selected PMs are seen to be relevant according to all the experts and management involved in the evaluation process. In addition, site-specific metrics could be fitted to the proposed framework.

The case study at two different sites with different specifications was able to demonstrate not only the general applicability, but also the benefits of the modularisation approach. This allowed an efficient implementation of the PMS at the two focus sites. Furthermore, all the relevant process steps of the logistics processes at the two sites were 
able to be implemented in the PMS, highlighting an exhaustive coverage of the applied logistics processes by our modules. In addition, this logic showed significant benefits during IT implementation, where it facilitated the development of a standardised dashboard-allowing eliminating manual workload for standard KPI evaluation. During the application phase of the PMS, the standardisation and modularisation proved its benefits in terms of the identification of improvement potentials. Even though processes overall are typically hardly comparable, on a module level comparisons can lead to the identification of improvement potentials (e.g. in the picking process, in warehousing).

The need for further research can be seen in the evaluation and roll-out to non-vehicle manufacturing sites, e.g. engine and drive-train sites. By doing so, applicability to the whole scope of automotive manufacturing and logistics can be evaluated. In addition, the required boundary conditions within a company to implement and actually constantly use such a PMS needs further research (e.g. acceptance of PIs and open culture regarding improvement ideas).

By further rolling out the proposed PMS to a first-tiersecond-tier relationship, the applicability for the automotive chain can be evaluated further as, up to now, the applicability could only be proven in a relationship with OEM involvement.

Following up on the results of our evaluation, an additional area for further research has been identified: How to properly design a performance-monitoring cockpit? This includes the presentation of results, but also the logic built into the system itself (e.g. advanced analytics and linked alerting functions). While the PIs and the PMS itself are seen to enable continuous improvement, some potential is still seen, further enabling the PMS's user to quickly identify the current state of logistics performance and potential improvements. We hope that the latest approaches in research and industry will offer improvement potentials for this area, e.g. carrying over big data discussions to autonomous performance evaluation.

Should the PMS find a broad application, an integration of the selected PIs, and their standardised definition, can be further recommended in supply chain management IT tools to address today's challenge that typically there is no aligned support of performance management by standard IT systems - this is seen as one reason for today's broadly varying PMS approaches.

We hope our research will further increase the discussion on PMS in automotive logistics and that our suggested approach forms the base for further rolling out PMS across the automotive supply chain.

\section{Compliance with ethical standards}

Conflict of interest The research project is part of cooperation between the Technische Universität München, Lehrstuhl für Fördertechnik Materialfluss Logistik and Volkswagen AG. Martin Dörnhöfer and Willibald A. Günthner are part of the joint project team from the Technische Universität München, Lehrstuhl für Fördertechnik Materialfluss Logistik. Falk Schröder is employed at Volkswagen AG, Wolfsburg.

Open Access This article is distributed under the terms of the Creative Commons Attribution 4.0 International License (http://crea tivecommons.org/licenses/by/4.0/), which permits unrestricted use, distribution, and reproduction in any medium, provided you give appropriate credit to the original author(s) and the source, provide a link to the Creative Commons license, and indicate if changes were made.

\section{Appendix}

See Fig. 17. 


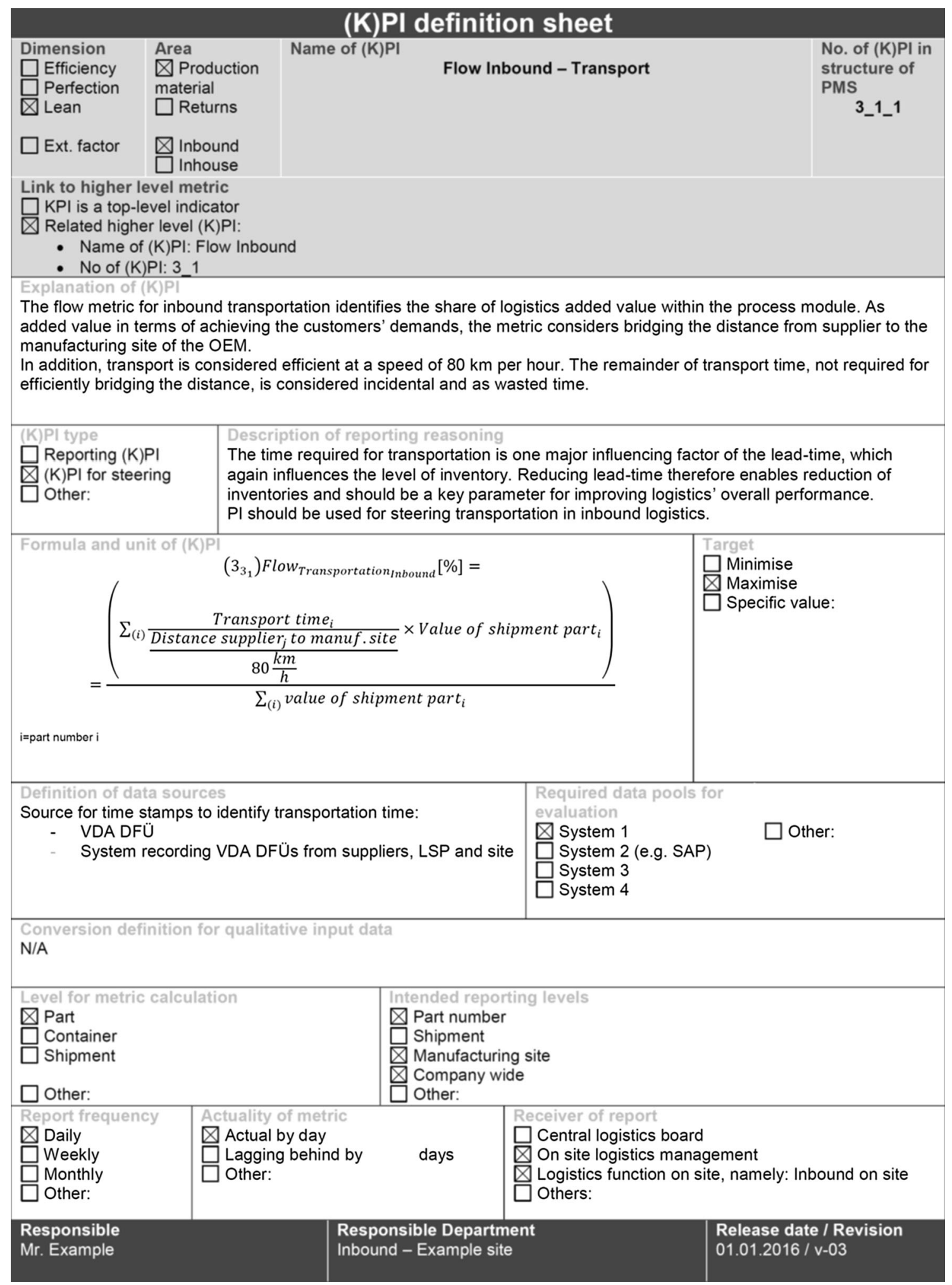

Fig. 17 Example for proposed (K)PI definition sheet using the definition of inbound transport flow metric 


\section{References}

1. Gunasekaran A, Patel C, McGaughey R (2004) A framework for supply chain performance measurement. Int $\mathrm{J}$ Prod Econ 87(3):333-347

2. Melnyk SA, Bititci U, Platts K, Tobias J, Andersen B (2014) Is performance measurement and management fit for the future? Manag Account Res 25:173-186

3. Schmitz J, Platts KW (2004) Supplier logistics performance measurement: indications from a study in the automotive industry. Int J Prod Econ 89(2):231-243

4. Forslund H, Jonsson P (2010) Selection, implementation and use of ERP systems for supply chain performance management. Ind Manag Data Syst 110(8):1159-1175

5. Danese P, Romano P (2012) Relationship between downstream integration, performance measurement systems and supply network efficiency. Int J Prod Res 50(7):2002-2013

6. Gunasekaran A, Kobu B (2007) Performance measures and metrics in logistics and supply chain management: a review of recent literature (1995-2004) for research and applications. Int J Prod Res 45(12):2819-2840

7. de Leeuw S, Beekman L (2008) Supply chain-oriented performance measurement for automotive spare parts. Int $\mathrm{J}$ Automot Technol Manag 8(1):56-70

8. Caplice C, Sheffi Y (1994) A review and evaluation of logistics metrics. Int J Logist Manag 5(2):11-28

9. Neto MS, Pires S (2012) Performance measurement in supply chains: a study in the automotive industry [Medição de desempenho em cadeias de suprimentos: Um estudo na indústria automobilística]. Gestao e Producao 19(4):733-746

10. Gunasekaran A, Williams H, McGaughey R (2005) Performance measurement and costing system in new enterprise. Technovation 25(5):523-533

11. Jones DT, Hines P, Rich N (1997) Lean logistics. Int J Phys Distrib Logist Manag 27(3):153-173

12. Neely A, Mills J, Platts K, Gregory M, Richards H (1996) Performance measurement system design: should process based approaches be adopted? Int J Prod Econ 46-47:423-431

13. Behrouzi F, Wong KY (2011) A study on lean supply chain performance measures of SMEs in the automotive industry. In: IEEE international conference on industrial engineering and engineering management

14. Womack JP, Jones DT, Roos D (1991) The machine that changed the world. How Japan's secret weapon in the global auto wars will revolutionize western industry, 1st edn. HarperPerennial, New York

15. Folan P, Browne J (2005) A review of performance measurement: towards performance management. Comput Ind 56(7):663-680

16. Schmitz J, Platts KW (2004) Supplier logistics performance measurement: indications from a study in the automotive industry. Int J Prod Econ 89:231-243

17. Stainer A (1997) Logistics: a productivity and performance perspective. Supply Chain Manag 2(2):53-62

18. Cagnazzo L, Taticchi P, Brun A (2010) The role of performance measurement systems to support quality improvement initiatives at supply chain level. Int $\mathbf{J}$ Product Perform Manag 59(2):163-185

19. Kaplan RS, Norton DP (1996) The balanced scorecard. Harvard Business School Press, Boston

20. Gunasekaran A, Patel C, Tirtiroglu E (2001) Performance measures and metrics in a supply chain environment. Int J Oper Prod Manag 21(1):71-87

21. Bendoly E, Rosenzweig E, Stratman J (2007) Performance metric portfolios: a framework and empirical analysis. Prod Oper Manag 16(2):257-276
22. Andersson P, Aronsson H, Storhagen NG (1989) Measuring logistics performance. Eng Costs Prod Econ 17(1-4):253-262

23. Bititci US (1995) Modelling of performance measurement systems in manufacturing enterprises. Int J Prod Econ 42:137-147

24. Agus A, Hajinoor MS (2012) Lean production supply chain management as driver towards enhancing product quality and business performance. Int J Qual Reliab Manag 29(1):92-121

25. Globerson S (1985) Issues in developing a performance criteria system for an organization. Int J Prod Res 23(4):639-646

26. Caplice C, Sheffi Y (1995) A review and evaluation of logistics performance measurement systems. Int $\mathrm{J}$ Logist Manag 6(1):61-74

27. Seuring SA, Müller M, Westhaus M, Morana R (2005) Conducting a literature review: the example of sustainability in supply chains. In: Kotzab H, Westhaus M (eds) Research methodologies in supply chain management. Physica-Verlag, Heidelberg, pp 91-106

28. Bentz TK (1974) Über Kennzahlen zur Planung, Steuerung und Kontrolle des Materialflusses für den optimalen Produktionsablauf, Berlin

29. Syska A (1990) Kennzahlen für die Logistik. Springer, Berlin

30. Karlsson C, Ahlstrom P (1996) Assessing changes towards lean production. Int J Oper Prod Manag 16(2):24-41

31. Soriano-Meier H, Forrester PL (2002) A model for evaluating the degree of leanness of manufacturing firms. Int $\mathbf{J}$ Integr Manuf Syst 13(2):104-109

32. Arif-Uz-Zaman K, Nazmul AMM (2014) Lean supply chain performance measurement. Int $\mathrm{J}$ Product Perform Manag 63(5):588-612

33. Wee HM, Wu S (2009) Lean supply chain and its effect on product cost and quality: a case study on ford motor company. Supply Chain Manag Int J 14(5):335-341

34. Wan H, Chen FF, Rivera L (2007) Leanness score of value stream maps. In: Proceedings of the 2007 industrial engineering research conference

35. Fullerton RR, Wempe WF (2009) Lean manufacturing, non-financial performance measures, and financial performance. Int $\mathrm{J}$ Oper Prod Manag 29(3):214-240

36. Karim A, Arif-Uz-Zaman K (2013) A methodology for effective implementation of lean strategies and its performance evaluation in manufacturing organizations. Bus Process Manag $\mathbf{J}$ 19(1):169-196

37. Leung S, Lee WB (2004) Strategic manufacturing capability pursuance: a conceptual framework. Benchmarking 11(2):156-174

38. Monden Y (2012) Toyota production system. An integrated approach to just-in-time, 4th edn. CRC Press, Boca Raton

39. Forslund $H$ (2007) Measuring information quality in the order fulfilment process. Int J Qual Reliab Manag 24(5):515-524

40. Bullinger H, Kühner M, van Hoof A (2002) Analysing supply chain performance using a balanced measurement method. Int $\mathrm{J}$ Prod Res 40(15):3533-3543

41. Wouters M, Wilderom C (2008) Developing performance-measurement systems as enabling formalization: a longitudinal field study of a logistics department. Acc Organ Soc 33(4-5):488-516

42. Seuring SA, Müller M, Westhaus M, Morana R (2008) Assessing the rigor of case study research in supply chain management. Supply Chain Int J 13(2):128-137

43. Craighead CW, Hanna JB, Gibson BJ, Meredith JR (2007) Research approaches in logistics. Int J Logist Manag 18(1):22-40

44. Göpfert I (2011) Einführung in die Logistik. Supply Chain Management und Logistikcontrolling, 3rd edn. Vahlen, Franz

45. Chan F, Qi HJ (2003) An innovative performance measurement method for supply chain management. Supply Chain Manag 8(3):209-223 
46. Cabral I, Grilo A, Cruz-Machado V (2012) A decision-making model for lean, agile, resilient and green supply chain management. Int J Prod Res 50(17):4830-4845

47. Supply Chain Council (2008) SCOR. Supply chain operations reference model, 9th edn. Supply Chain Council, USA

48. VDI (2012) Ganzheitliche Produktionssysteme, Grundlagen, Einführung und Bewertung. Verein Deutscher Ingenieure e.V., Düsseldorf 03.100.50 (2870)

49. Lohmann C, Fortuin L, Wouters M (2004) Designing a performance measurement system: a case study. Eur J Oper Res 156:267-286

50. Wilderom C, Wouters M, van Brussel J (2007) Balanced leadership, professionalism, and team trust predict positive attitudes toward performance measurement. Academy of Management 2007 Annual Meeting: Doing Well by Doing Good, AOM 2007

51. McCutcheon D, Meredith JR (1993) Conducting case study research in operations management. J Oper Manag 11:239-256

52. Wang X, Zhang J (2010) System measurement research on supply chain. In: Proceedings-3rd international conference on information management, innovation management and industrial engineering, ICIII 20104

53. Continental Automotive Group (2014) Supplier manual logistics. Global logistics standards and processes of continental automotive. http://www.conti-online.com/www/download/auto motive_de_en/general/download/supplier_manual_logistics_en. pdf. Accessed 22 June 2015

54. Kayakutlu G, Buyukozkan G (2011) Assessing performance factors for a $3 \mathrm{PL}$ in a value chain. Int $\mathrm{J}$ Prod Econ 131(2):441-452

55. Klug F (2011) Aktuelle trends in der Automobillogistik. Zeitschrift für die gesamte Wertschöpfungskette der Automobilwirtschaft (ZfAW) 3:60-68

56. Göbel W (2014) Effiziente Fertigfahrzeuglogistik im Spannungsfeld von Nachfrageverschiebungen, ökologischen Ansprüchen und Wirtschaftlichkeit, Garching bei München

57. Günthner WA, Dörnhöfer M (2015) Einsatz von Kennzahlensystemen in der Automobillogistik. Aktueller Entwicklungsstand und Handlungsbedarf. Lehrstuhl für Fördertechnik Materialfluß Logistik (fml) TU München, Garching b. München

58. Forslund H, Jonsson P (2009) Obstacles to supply chain integration of the performance management process in buyer-supplier dyads: the buyer's perspective. Int J Oper Prod Manag 29(1):77-95 